\title{
PROCESSAMENTO E APLICAÇÃO DE BIOMATERIAIS POLIMÉRICOS: AVANÇOS RECENTES E PERSPECTIVAS
}

\author{
Marcela Piassi Bernardo ${ }^{a}$, Rafaella Takehara Paschoalin ${ }^{\mathrm{b}}$, Danilo Martins dos Santos ${ }^{\mathrm{a}}$, Stanley Bilatto ${ }^{\mathrm{a}}$, Cristiane Sanchez \\ Farinasa $^{a}$, Daniel Souza Correa ${ }^{a}$, Osvaldo N. Oliveira Jr. ${ }^{\mathrm{b}}$ e Luiz Henrique Capparelli Mattoso ${ }^{\mathrm{a}, *,(]}$ \\ a Laboratório Nacional de Nanotecnologia para o Agronegócio, Embrapa Instrumentação, 13561-206 São Carlos - SP, Brasil \\ 'Instituto de Física de São Carlos, Universidade de São Paulo, 13566-590 São Carlos - SP, Brasil \\ Recebido em 15/03/2021; aceito em 18/05/2021; publicado na web em 16/06/2021
}

\begin{abstract}
PROCESSING AND APPLICATION OF POLYMERIC BIOMATERIALS: RECENT ADVANCES AND PERSPECTIVES. Biomaterials have been intensively investigated due to the increase in the elderly population and high prevalence of several disorders, such as cardiovascular and orthopedic diseases. Polymeric and composite polymeric materials in combination with different processing techniques, such as electrospinning, solution blow spinning, ultrathin film preparation, and 3D printing are promising for obtaining biomaterials with patient-specific applications. Here, we provide a review on recent advances and perspectives for synthetic and natural polymers as well as composites in the design of biomaterials. After introducing basic information about biomaterials, we describe the fundamentals of manufacturing techniques and highlight possible biomedical applications.
\end{abstract}

Keywords: tissue engineering; films; solution blow-spinning; electrospinning; 3D printing.

\section{INTRODUÇÃO}

Biomateriais têm sido definidos de diferentes maneiras ao longo da história; nesta revisão consideraremos biomaterial como qualquer substância, ou combinação de substâncias, diferentes de fármacos que possam interagir com sistemas biológicos com o objetivo de tratar, aumentar ou substituir quaisquer tecidos, órgãos ou funções do corpo. ${ }^{1}$ Devem satisfazer uma série de requisitos, entre os quais se destacam: permitir crescimento e proliferação celular, serem biodegradáveis a taxas semelhantes à de crescimento do tecido original, serem biocompatíveis, serem capazes de entregar fatores de crescimento e terem propriedades mecânicas adequadas com formatos apropriados. ${ }^{2}$ Ainda, os biomateriais podem ser classificados em: (i) bioinertes, quando o biomaterial tem interação mínima com os tecidos circundantes $;^{3}$ (ii) bioreabsorvíveis, quando o biomaterial é dissolvido, ou reabsorvido após contato com tecidos; ${ }^{3}$ (iii) bioativos, quando após implantação é provocada uma resposta biológica específica na interface do biomaterial, que resulta na formação de uma ligação entre o tecido e o material. Em outras palavras, os biomateriais bioativos têm capacidade de induzir e conduzir uma resposta do sistema biológico; ${ }^{3}$ (iv) biomiméticos têm sua estrutura inspirada em modelos existentes na natureza, por exemplo, a estrutura hexagonal da colmeia de abelhas, o desenho da teia de aranha ou os espinhos do ouriço. ${ }^{4}$

Dentre as classes de materiais mais utilizadas como biomateriais estão os metais, polímeros, cerâmicas ou a combinação destes ${ }^{5,6}$ Por suas propriedades mecânicas, os metais podem substituir tecidos duros, como articulações de quadril, raízes de dentes e placas ósseas. São utilizados majoritariamente na forma de ligas metálicas, como o aço inoxidável, ligas de cobalto e de titânio. ${ }^{7}$ Uma possível desvantagem está nos efeitos tóxicos de elementos como níquel, cromo e cobalto. ${ }^{8}$ As cerâmicas são caracterizadas pela resistência à corrosão e desgaste, dureza e rigidez. Podem ser classificadas como inertes, quando não são absorvidas pelo corpo (alumina e zircônia); semi-inertes quando são bioativas ou com superfície reativa (cerâmicas vítreas); e não-inertes quando são biodegradáveis e

*e-mail: luiz.mattoso@embrapa.br reabsorvíveis (aluminatos e fosfatados de cálcio). O uso de materiais cerâmicos é restrito a casos em que não é necessária elevada resistência mecânica, como em implantes dentários e otológicos. ${ }^{1,9,10}$

Os polímeros, sintéticos e naturais, formam a classe com maior diversidade de biomateriais, em parte devido à grande variedade de composições e propriedades. ${ }^{11}$ Apresentam maior versatilidade em termos de processabilidade e modificação que metais e cerâmicas, permitindo potencializar ou conferir novas propriedades aos materiais para diversas aplicações. ${ }^{12}$ A modulação das características físicoquímicas, mecânicas e biológicas dos biomateriais pode ser realizada combinando-se polímeros, cerâmicas e metais, ou seja, formando compósitos. Por exemplo, a incorporação de cerâmicas a matrizes poliméricas podem gerar compósitos com elevadas propriedades mecânicas. ${ }^{13,14}$ Quando a fase dispersa (particulada) tem pelo menos uma de suas dimensões inferior a 100 nanômetros (nm) são obtidos nanocompósitos. Biomateriais nanoestruturados constituem uma alternativa aos materiais macroestruturados ou microestruturados, pois suas propriedades podem ser superiores, considerando que a redução da dimensão dos materiais à escala nanométrica possibilita maior interação entre os componentes. ${ }^{15}$ Tais nanocompósitos são aplicados em preenchimentos dentários e implantes ortopédicos. ${ }^{16}$ Ressalta-se que um biomaterial com dimensões macrométricas pode ser nanoestruturado e demonstrar propriedades características de materiais nanométricos.

Neste artigo de revisão, serão discutidos avanços recentes e perspectivas no uso de biomateriais poliméricos e compósitos. Serão abordadas as principais técnicas para fabricação de biomateriais para aplicações biomédicas, com ênfase aos métodos de eletrofiação, fiação por sopro, técnicas de formação de filmes e impressão 3D.

\section{CONTEXTUALIZAÇÃO HISTÓRICA E ECONÔMICA}

No final da década de 1940, o oftalmologista Harold Ridley examinou pilotos de caça da II Guerra Mundial com perfurações nos olhos causados pelo polímero poli(metacrilato de metila) (PMMA), oriundo de estilhaços da cabine de pilotagem dos aviões. ${ }^{17}$ Harold notou que os machucados foram curados sem tratamento médico e reações adversas, e concluiu que esse polímero poderia ser usado 
para implantes oculares, como lentes em substituição às lentes naturais. Essa constatação abriu caminho para a primeira cirurgia de tratamento de catarata, realizada em 1949. Hoje são realizadas mais de 10 milhões de cirurgias por ano empregando versões modernas de lentes intraoculares baseadas na desenvolvida por Ridley. ${ }^{17} \mathrm{Na}$ década de 1960, cientistas de engenharia, química e biologia, e profissionais da medicina iniciaram a formalização dos princípios e estratégias para obtenção dos biomateriais. ${ }^{17}$ Foram estabelecidos os critérios a serem satisfeitos pelos biomateriais para aplicações médicas. $\mathrm{O}$ primeiro deles é que os biomateriais devem ser facilmente purificados, fabricados e esterilizáveis por métodos convencionais. Além disso, essas estruturas devem ter propriedades mecânicas (resistência à tensão, à compressão e ao cisalhamento) compatíveis com os tecidos nos quais serão implantados, e serem biocompatíveis, ou seja, não liberarem substâncias que resultem em reações indesejadas, incluindo inflamações, necrose de tecidos, ou alergias. ${ }^{13}$

$\mathrm{O}$ uso de biomateriais movimentaram nos últimos 50 anos cerca de 100 bilhões de dólares. ${ }^{17}$ Estima-se o uso anual de cerca de 1 bilhão de cateteres, 150 milhões de lentes de contato e 7 milhões de lentes intraoculares. Somam-se a esses números entre 1 e 2,5 milhões de próteses de joelho, quadril e ombro, dispositivos para hemodiálise e oxigenação sanguínea, stents cardiovasculares, parafusos e placas de fixação óssea, tubos auriculares e dispositivos intrauterinos. A maior parcela do mercado de biomateriais concentra-se nos EUA (43\%), seguido da Europa (33\%), Ásia (3\%) e Brasil (2\%). Os 19\% restantes são distribuídos por outros países. ${ }^{18}$

\section{BIOMATERIAIS POLIMÉRICOS}

\section{Polímeros naturais}

Polímeros naturais são macromoléculas sintetizadas durante o ciclo de crescimento de organismos vivos através de reações catalisadas por enzimas e reações de crescimento de cadeia a partir de monômeros, os quais são formados dentro de células por processos metabólicos complexos. ${ }^{19}$ Os polímeros naturais podem ser classificados em proteínas (ex.: colágeno, gelatina, zeína e fibroína), polissacarídeos (ex.: celulose, quitina, quitosana, alginato, e ácido hialurônico), polinucleotídeos, poli-isoprenos (ex. borracha natural), poliésteres (ex.: poli(b-hidroxibutirato) (PHB), poli(b-hidroxivalerato) (PHV) e poli(hidroxibutirato-covalerato) (PHB-V)). ${ }^{20}$ Essas macromoléculas têm sido amplamente utilizadas no desenvolvimento de biomateriais em função da grande disponibilidade, biocompatibilidade, biodegradabilidade e não-toxicidade. ${ }^{21-23}$ Nesta seção, serão discutidas as principais características de biopolímeros com ênfase em polissacarídeos, apresentando as vantagens e desvantagens dessas macromoléculas como matérias-primas para elaboração de biomateriais, conforme listado na Tabela 1.

\section{Celulose}

A celulose é o polímero natural mais abundante na biosfera, constituída por unidades de monossacarídeo $\beta$-D-glucopiranose ligadas $(1 \rightarrow 4) . .^{54-58}$ É encontrada majoritariamente nas células de plantas, mas também pode ser produzida por algas, fungos e bactérias. ${ }^{59} \mathrm{~A}$ celulose bacteriana (CB) é biossintetizada em forma de membrana a partir da secreção das bactérias aeróbicas, Gram-negativas e não patogênicas do gênero Komagataeibacter (K. xylinus e K. hansenii) ${ }^{60}$ Sua síntese pode ser dividida em duas etapas: (I) formação intracelular das cadeias de $\beta$-1,4-glicosídicas e (II) montagem e cristalização das cadeias de celulose. Nesta última etapa, as cadeias de celulose são secretadas para fora da bactéria produzindo celulose extracelular em formato de fibrilas com estrutura 3D. ${ }^{61}$
A insolubilidade da celulose em água limita sua aplicação por dificultar a processabilidade, o que requer estratégias como derivatização (ex. esterificação, carboximetilação, e hidroxipropilação) ${ }^{62,63}$ Por isso, nanomateriais de celulose, como nanocristais de celulose ${ }^{64}$ nanofibrilas de celulose ${ }^{65}$ e celulose bacteriana, ${ }^{60}$ vêm sendo empregados. ${ }^{66}$ Essas nanoestruturas de celulose são usadas na forma de hidrogéis, filmes, aerogéis, nãotecidos, e em combinação com outras macromoléculas para melhorar propriedades físico-químicas, biológicas e mecânicas. ${ }^{67}$ A celulose bacteriana se destaca por sua estrutura porosa em nível nanométrico, o que facilita a permeação de oxigênio e nutrientes, e propriedades mecânicas adequadas para suturas cirúrgicas. Além disso, a CB se adapta à forma do local aplicado, reduz a dor, mantém o local úmido, acelera a cicatrização, reduz cicatrizes, forma uma barreira mecânica contra microrganismos patogênicos, possui manipulação simples e é facilmente esterilizável e atóxica. ${ }^{61,68}$

A avaliação da degradação de biomateriais em condições de aplicação no organismo e dos subprodutos gerados nesse processo é de fundamental importância, uma vez que o material deve ser estável conforme a finalidade de uso e os produtos de degradação não devem ser tóxicos ou causar quaisquer tipos de efeitos adversos ao paciente. ${ }^{69}$ No caso das estruturas à base de celulose, as células do corpo humano não produzem enzimas capazes de clivar a ligação $\beta(1 \rightarrow 4)$ entre as duas frações de glicose desse polímero. ${ }^{70}$ Assim, a degradação da celulose nos tecidos ocorre por mecanismo de hidrólise não-enzimática da ligação $\beta(1 \rightarrow 4)$ cuja cinética é lenta e depende da quantidade de fluido corporal na área de implante bem como da difusividade de água no biomaterial. ${ }^{71}$ Apesar da degradação lenta, a celulose é biocompatível, têm bioestabilidade, citocompatibilidade e propriedades mecânicas adequadas para engenharia de tecidos, medicina regenerativa, curativos e liberação controlada de fármacos. ${ }^{72-74}$

\section{Quitina e quitosana}

A quitina consiste no segundo polímero mais abundante na biosfera e constitui o componente estrutural esquelético de invertebrados como artrópodes, moluscos, anelídeos, e celenterados. ${ }^{75,76}$ Também está presente em algas diatomáceas e nas paredes celulares de alguns fungos do grupo dos zigomicetes, ascomicetos, deuteromicetos, e basidiomicetos. A quitina é formada por unidades 2-amino-2-desoxiD-glucopiranose (GlcN) e 2-acetamido-2-desoxi-D-glucopiranose (GlcNAc) unidas por ligações glicosídicas do tipo $\beta(1 \rightarrow 4)$, em que há predomínio de unidades GlcNAc. ${ }^{75,77}$ Em função de sua hipoalergenicidade, biocompatibilidade, não-toxicidade, bioatividade e biodegradabilidade, a quitina é usada em membranas, filmes, esponjas, géis e nanofibras para aplicações biomédicas. ${ }^{77-79}$ É solúvel em poucos sistemas solventes, os quais são geralmente caros e tóxicos. Por isso, empregam-se estratégias como derivatização ${ }^{75,80} \mathrm{ou}$ preparo de nanocristais de quitina ${ }^{81}$ para melhorar a processabilidade. Nanocristais de quitina, também conhecidos como whiskers de quitina, são preparados principalmente por processos como hidrólise ácida ou oxidação mediada por radical 2,2,6,6-tetrametilpiperidina1-oxil (TEMPO) que removem a parte amorfa da quitina. ${ }^{79}$ Essas nanoestruturas são usadas para formar filmes, ${ }^{82}$ membranas porosas ${ }^{83}$ e em reforço de matrizes poliméricas. ${ }^{84}$

A quitosana pode ser encontrada em algumas espécies de fungos, mas é geralmente obtida a partir da reação de $N$-desacetilação da quitina em meio básico. ${ }^{75,85,86}$ Assim como a quitina, a quitosana é um copolímero linear formado por unidades 2-amino-2-desoxiD-glucopiranose $(G l c N)$ e 2-acetamido-2-desoxi-D-glucopiranose $(G l c N A c)$ unidas por ligações glicosídicas do tipo $\beta(1 \rightarrow 4)$, porém com predomínio de unidades $G l c N .{ }^{85,87}$ As propriedades físico-químicas, biológicas e de processabilidade da quitosana são influenciadas 
Tabela 1. Biopolímeros e estruturas de suas unidades repetitivas, características e aplicações no desenvolvimento de materiais voltados para aplicações biomédicas

Polímero

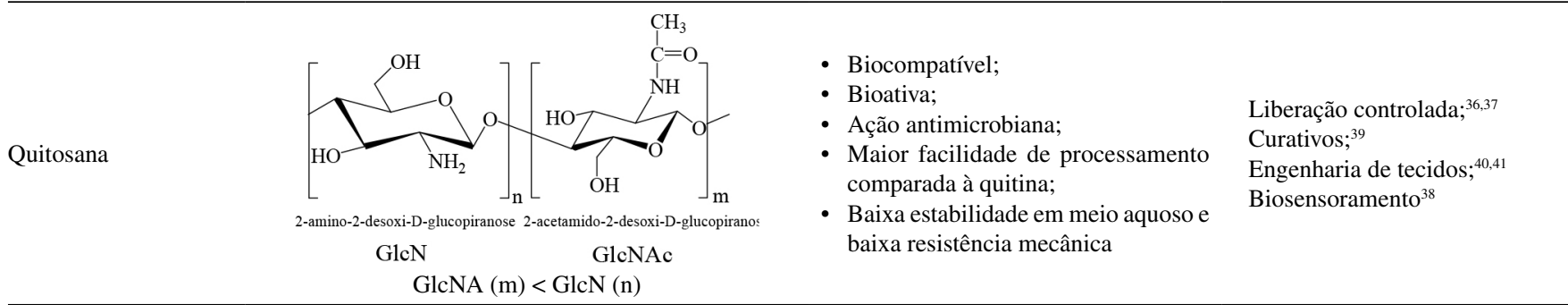

Alginato

* Estrutura da celulose: imagem adaptada da Ref. ${ }^{54}$ Copyright 2005 Wiley; Estruturas da quitina e quitosana: imagens adaptadas da Ref. ${ }^{55}$ Copyright 2011 Elsevier; Estrutura do alginato: imagem adaptada da Ref. ${ }^{56}$ Copyright 2020 American Chemical Society; Estrutura do ácido hialurônico: imagem adaptada da Ref. ${ }^{57}$ Copyright 2020 Wiley.

pela massa molar média e grau médio de acetilação $(\overline{\mathrm{GA}})$, que corresponde ao número médio de unidades glucosamina na cadeia do polímero. Diferentemente da quitina, a quitosana é solúvel em solução aquosa diluída de ácidos (ex. ácidos acético e clorídrico). No corpo humano, a quitina e quitosana são degradadas principalmente pela enzima lisozima e os produtos de degradação não são tóxicos e não desencadeiam reações inflamatórias..$^{75,88} \mathrm{~A}$ taxa de degradação desses polímeros é dependente principalmente do grau médio de acetilação, sendo que quanto maior a proporção de unidades 2-amino-2-desoxi-D-glucopiranose $(\mathrm{GlcN})$, menor a degradação. ${ }^{89}$ Dentre as propriedades que tornam a quitosana útil para aplicações biomédicas estão a biocompatibilidade, biodegradabilidade, atoxicicidade e atividade antimicrobiana. ${ }^{90-92}$ Biomateriais de quitosana em membranas porosas, não-tecidos, ${ }^{93}$ nanopartículas, nanofibras, e filmes são usados em medicina regenerativa, engenharia de tecidos, liberação controlada de fármacos e em biossensores. Para conferir novas propriedades (ex. solubilidade em meio neutro e alcalino) e potencializar outras, como atividade antimicrobiana e mucoadesividade, modificam-se quitosanas através do grupo $-\mathrm{NH}_{2}$ ligado ao $\mathrm{C} 2$ da unidade $\mathrm{GlcN}$ e dos grupos $-\mathrm{OH}$ ligados aos carbonos
C3 e C6. ${ }^{94}$ Exemplos de derivatização incluem a carboximetilação, ${ }^{95}$ quaternização ${ }^{87,96}$ e peguilação. ${ }^{97}$

\section{Alginato}

$\mathrm{O}$ alginato é um copolímero aniônico linear constituído por unidades $\beta$-D-manuronato (M) e $\alpha$-L-guluronato $(\mathrm{G})$ unidas por ligações glicosídicas, conforme ilustrado na Tabela $1 .{ }^{22}$ As propriedades físico-químicas e biológicas dos alginatos dependem de sua fonte, sendo que há mais de 200 alginatos que diferem nas proporções e sequência de ligação das unidades M e G. ${ }^{22,98}$ Esse polímero é normalmente extraído de algas marrons, usado em aplicações biomédicas, pois os produtos de sua degradação são biocompatíveis. ${ }^{21}$ Materiais à base de alginato podem ser processados em diferentes estruturas tais como hidrogéis, ${ }^{43,45}$ membranas porosas ${ }^{99}$ e não-tecidos, ${ }^{100}$ os quais apresentam potencial de aplicação na regeneração óssea, ${ }^{45}$ como curativos, ${ }^{43}$ bem como na liberação de compostos bioativos tais como fármacos, enzimas, células e fatores de crescimento. ${ }^{101-103} \mathrm{~A}$ produção dessas estruturas geralmente envolve o uso de agentes reticulantes para aumentar a estabilidade em meio fisiológico, sendo mais utilizados os que promovem ligações iônicas 
(ex: $\mathrm{CaCl}_{2}$ ) ou covalentes (ex: modificação da estrutura do alginato com metacrilato seguida pela incidência de radiação luz na presença de fotoiniciador). ${ }^{21,42,98}$ Materiais à base de alginato estão sujeitos à dissolução quando implantados no corpo, sendo que as cadeias poliméricas com massa molar inferior a $50 \mathrm{kDa}$ podem ser removidas através do rim, ao passo que as cadeias de maior massa molar não são eliminadas por depuração renal e, como as células dos mamíferos não produzem enzimas capazes de degradar esse polímero, ele não se decomporá no corpo. ${ }^{104}$ Nesse sentido, estratégias de modificação do alginato por meio de processos de derivatização têm sido adotadas de modo a torná-lo mais suscetível a degradação no corpo. ${ }^{105,106}$

\section{Ácido hialurônico}

O ácido hialurônico (HA) é um copolímero aniônico linear constituído por unidades dissacarídicas de ácido D-glicurônico e $\mathrm{N}$-acetilglicosamina, unidas alternadamente por ligações do tipo $\beta(1 \rightarrow 3)$ e $\beta(1 \rightarrow 4)$ (Tabela 1$).{ }^{23}$ Esse polímero pode ser extraído de tecidos animais, tais como cordão umbilical e crista de galo, ou produzido por fermentação microbiana. ${ }^{107,108}$ Como em outros polímeros, as propriedades físico-químicas e biológicas do HA dependem de sua massa molar, associada à fonte e características do processo de extração. ${ }^{23,107,108} \mathrm{O}$ HA é um dos principais componentes da matriz extracelular e atua no mecanismo de hidratação dos tecidos. É biodegradável, não-imunogênico, pode estimular a proliferação e diferenciação celular e tem ação anti-inflamatória. ${ }^{109}$ Essas propriedades o tornam atraente para cirurgias oftalmológicas, cirurgias cosméticas e de reconstrução, sistemas carreadores de compostos bioativos, regeneração óssea e em curativos..$^{23,50,109-111}$
Em meio fisiológico, materiais à base de HA podem ser degradados rapidamente via hidrólise enzimática por hialuronidases naturalmente presentes no corpo ou por hidrólise não-enzimática. ${ }^{109,112}$ A fim de controlar a taxa de degradação e melhorar as propriedades mecânicas dessas estruturas, diferentes estratégias tais como reticulação química ou física, bem como a modificação química das cadeias de HA, têm sido propostas para a obtenção de materiais mais estáveis em condições de aplicação no corpo. ${ }^{113,114}$

\section{Polímeros sintéticos}

Polímeros sintéticos são usados em aplicações biomédicas, ${ }^{115}$ pois suas propriedades podem ser controladas com ajustes na rota sintética. Propriedades como cristalinidade, temperatura de fusão e transição vítrea, massa molar e formação de grupos laterais, dependem dos monômeros empregados, dos iniciadores, aditivos e condições de reação. ${ }^{116-118}$ Os principais polímeros sintéticos e aplicações estão representados na Tabela 2 .

\section{Poliésteres alifáticos e seus copolímeros}

Os poliésteres são termoplásticos com ligações ésteres alifáticas. Como biomateriais, os mais relevantes são o poli(ácido láctico) (PLA), poli(ácido glicólico) (PGA) e seus copolímeros, poli(ácido láctico-co-ácido glicólico) (PLGA), poli( $\varepsilon$-caprolactona) (PCL), polihidroxialcanoatos (PHAs) e poli(3-hidroxibutirato) (PHB). ${ }^{145}$ São polímeros aprovados pelo Food \& Drug Administration (FDA) dos Estados Unidos para várias aplicações clínicas, ${ }^{146,147}$ sendo biodegradáveis pois suas cadeias carbônicas permitem degradação

Tabela 2. Biopolímeros sintéticos e estruturas de suas unidades repetitivas, características e aplicações no desenvolvimento de materiais voltados para aplicações biomédica

\begin{tabular}{|c|c|c|c|}
\hline Polímero & Estrutura & Características & Aplicações \\
\hline Poli(ácido láctico) & & $\begin{array}{l}\text { - Biocompatível; } \\
\text { - Biodegradável; } \\
\text { - Obtido por fontes renováveis; } \\
\text { - Elevado modo de elasticidade e } \\
\text { rigidez; } \\
\text { - Fácil processabilidade }\end{array}$ & $\begin{array}{l}\text { Liberação controlada; } ;^{119,120} \\
\text { Curativos; }{ }^{121,122} \\
\text { Engenharia de tecidos; }{ }^{123} \\
\text { Biosensoramento }\end{array}$ \\
\hline Poli(ácido glicólico) & & $\begin{array}{l}\text { - Biocompatível; } \\
\text { - Biodegradável; } \\
\text { - Obtido por fontes renováveis; } \\
\text { - Estável em meio aquoso; } \\
\text { - Fácil processabilidade } \\
\end{array}$ & $\begin{array}{l}\text { Liberação controlada; } ;^{125} \\
\text { Curativos; }{ }^{126} \\
\text { Engenharia de tecidos; }{ }^{127} \\
\text { Biosensoramento }^{128}\end{array}$ \\
\hline Poli(E-caprolactona) & & $\begin{array}{l}\text { - Biocompatível; } \\
\text { - Apresenta bioatividade; } \\
\text { - Ação antimicrobiana; } \\
\text { - Maior facilidade de processa- } \\
\text { mento comparada à quitina; } \\
\text { - Baixa estabilidade em meio aquo- } \\
\text { so e baixa resistência mecânica } \\
\end{array}$ & $\begin{array}{l}\text { Liberação controlada; }{ }^{129} \\
\text { Curativos; }{ }^{130} \\
\text { Engenharia de tecidos; }{ }^{131} \\
\text { Biosensoramento }^{132}\end{array}$ \\
\hline Polihidroxialcanoatos & & $\begin{array}{l}\text { - Biocompatível; } \\
\text { - Produzido por bactérias; } \\
\text { - Boas propriedades mecânicas; } \\
\text { - Fácil processabilidade }\end{array}$ & $\begin{array}{l}\text { Liberação controlada; }{ }^{133} \\
\text { Curativos } ;^{134} \\
\text { Engenharia de tecidos; }{ }^{135} \\
\text { Biosensoramento }\end{array}$ \\
\hline Poli(éter-éter-cetona) & & $\begin{array}{l}\text { - Biocompatível; } \\
\text { - Baixa solubilidade; } \\
\text { - Resistência; } \\
\text { - Excelentes propriedades mecâni- } \\
\text { - cas; } \\
\text { - Difícil processamento } \\
\end{array}$ & $\begin{array}{l}\text { Liberação controlada; }{ }^{137} \\
\text { Curativo; }{ }^{138} \\
\text { Engenharia de tecidos; }{ }^{139} \\
\text { Biosensoramento }^{140}\end{array}$ \\
\hline Poliuretanos & & $\begin{array}{l}\text { - Biocompatível; } \\
\text { - Origem natural (óleo da ma- } \\
\text { mona); } \\
\text { - Flexível; } \\
\text { - Difícil reciclagem } \\
\end{array}$ & $\begin{array}{l}\text { Liberação controlada; }{ }^{141} \\
\text { Curativos; }{ }^{142} \\
\text { Engenharia de tecidos }{ }^{143} \\
\text { Biosensoramento }{ }^{144}\end{array}$ \\
\hline
\end{tabular}


via hidrólise ou ataque enzimático e são facilmente excretados do corpo humano. ${ }^{148} \mathrm{~A}$ síntese de PLA envolve o uso do ácido láctico obtido de diferentes fontes renováveis. ${ }^{149}$ Como tem um carbono quiral e dois estereoisômeros, ou seja, L-ácido láctico e D-ácido láctico, o PLA pode ser sintetizado como cadeias compostas por L-ácido láctico (PLLA), por D-ácido láctico (PDLA), ou uma mistura racêmica (PDLLA). ${ }^{150} \mathrm{~A}$ composição dos enantiômeros no polímero final determina suas propriedades. ${ }^{151}$

O PGA tem tipicamente alta massa molar e baixa solubilidade na maioria dos solventes orgânicos, mas suas formas de baixa massa molar são mais solúveis. ${ }^{152}$ O PLGA é um copolímero superior a seus homólogos, sendo que suas propriedades químicas, mecânicas e estruturais dependem de sua composição. Por exemplo, grande proporção de PLA no copolímero pode levar ao aumento do tempo de degradação; enquanto o aumento de PGA pode ter efeito contrário. ${ }^{153}$

O PCL é um polímero semicristalino solúvel em solventes orgânicos. É usado em aplicações biomédicas, sozinho ou em combinação com outros polímeros sintéticos ou naturais. ${ }^{154}$ Seus perfis de degradação dependem de sua massa molar e do grau de cristalinidade, sendo a taxa de degradação semelhante à de formação de tecidos ósseos. ${ }^{155}$ Em contraste, a degradação por clivagem não enzimática do PCL é mais lenta do que para polímeros como PLA e PGA. ${ }^{156}$

Os polihidroxialcanoatos (PHAs) podem ser sintetizados de matérias-primas renováveis na agricultura. ${ }^{157}$ A síntese de PHA por bactérias em meio nutritivo ocorre quando há excesso de carbono e limitação de pelo menos um nutriente necessário à multiplicação das células, como nitrogênio, fósforo, magnésio e ferro. ${ }^{158} \mathrm{O}$ termoplástico dessa família mais estudado é o poli(hidroxibutirato) (PHB), usado como suporte para a regeneração de tecido nervoso ${ }^{159}$ e ósseo. ${ }^{26}$ É biocompatível ${ }^{160}$ e seus produtos de degradação não apresentam toxicidade, ${ }^{26}$ sendo absorvidos por vias metabólicas. Para a engenharia de tecidos, os mais relevantes são os copolímeros poli(3hidroxibutirato) (PHB), 3-hidroxibutirato e 3-hidroxivalerato (PHBV), poli(4-hidroxibutirato) (P4HB), 3- copolímeros de hidroxibutirato e 3-hidroxihexanoato (PHBHHx) e poli(3-hidroxioctanoato) (PHO). O uso de PHB é limitado por sua fragilidade, alto grau de cristalinidade, ${ }^{26}$ baixa rigidez, caráter hidrofóbico e lenta taxa de degradação. Essas propriedades podem ser melhoradas com métodos de produção de materiais de suporte e com a modificação da superfície.

\section{Poli(éter-éter-cetona) (PEEK)}

PEEK é um termoplástico orgânico de cadeia linear, semicristalino com alto desempenho e alta resistência ao desgaste. É biocompatível, quimicamente estável, radiolucente e com módulo elástico semelhante ao do osso natural. ${ }^{161}$ Foi usado inicialmente como biomaterial para reparar articulações do joelho, ${ }^{162}$ fusão espinhal (espondilodese) ${ }^{163}$ e reparo craniofacial. ${ }^{164}$ Estudos recentes mostram que o PEEK é biologicamente inerte, não interagindo com o tecido vivo por apresentar baixa bioatividade. Estratégias estão sendo adotadas para modificar sua superfície para aumentar a bioatividade, por exemplo com lixiviação de partículas, que por meio da formação de poros pode alterar a rugosidade da superfície do polímero e assim melhorar a interação com células e tecidos. ${ }^{165}$ A biocompatibilidade dos compósitos PEEK foi confirmada em estudos de citotoxicidade in vitro $^{165-169} \mathrm{e}$ in vivo, em que o biomaterial causou resposta inflamatória mínima, ${ }^{16,170,171}$ podendo ser usado para estimulação e integração com o tecido local. ${ }^{172,173}$

\section{Poliuretanos (PUs)}

PUs representam uma classe versátil de biomateriais, formados por blocos de segmentos alternados flexíveis e segmentos rígidos unidos por ligações uretano. ${ }^{174}$ São termoplásticos e termofixos cujas propriedades mecânicas, térmicas e químicas podem ser controladas com ajustes na rota sintética. ${ }^{175,176}$ Apresentam biocompatibilidade, biodegradabilidade, elasticidade, não são imunogênicos e têm propriedades mecânicas comparáveis aos tecidos naturais. ${ }^{177-179} \mathrm{Os}$ principais constituintes dos PUs são polímeros naturais ou sintéticos, puros ou em mistura de fases. Os PUs biodegradáveis são formados de diisocianatos alifáticos contendo diferentes polióis e extensores de cadeia como diois, diaminas e disulfetos. ${ }^{180}$ As propriedades de degradação dos polímeros são essenciais para escolher biomateriais eficientes na regeneração de tecidos. ${ }^{181}$ Elastômeros de poliuretanos são biocompatíveis e versáteis por suas propriedades mecânicas, força elástica e resistência à fadiga. A deformação elástica ocorre devido às ligações de hidrogênio entre os grupos uretanos, o que pode ser explorado em tecidos que necessitam de elasticidade como em tecidos mole. ${ }^{182}$ PUs são empregados em aplicações biomédicas e farmacêuticas incluindo filtros antimicrobianos, usados em cateteres, tubos endotraqueais e filtros sanguíneos - para evitar contaminação por microrganismos e formação de biofilmes e futuros casos de infecção -, biossensores, materiais para curativos de feridas, liberação controlada de fármacos, e como arcabouços (scaffolds) para engenharia de tecidos. ${ }^{144,175,183,184}$

\section{Compósitos}

Compósitos são formados por fases distintas entre si, separados em escala maior que a atômica. A combinação de materiais é uma alternativa para superar limitações em diferentes propriedades (mecânicas, físicas e biológicas) que os componentes apresentam separadamente, tornando-os aptos a novas aplicações, inclusive na engenharia de tecidos. ${ }^{15}$ Como grande parte dos tecidos humanos são constituídos por compósitos reais, esses materiais são estudados para reconstrução de tecidos, uma vez que o principal objetivo da engenharia de tecidos é a recuperação, manutenção ou melhora das funções de tecidos. ${ }^{185,186} \mathrm{~A}$ estrutura e características químicas de cada um dos materiais precursores ditarão o comportamento dos compósitos aplicados em organismos vivos. ${ }^{187}$

Compósitos e nanocompósitos podem ser formados pela mistura de (nano)partículas metálicas ou cerâmicas, fibras ou folhas a matrizes poliméricas. Diferentes técnicas, físicas e químicas, foram desenvolvidas para a produção de nanopartículas. A síntese de nanopartículas por métodos físicos requer menor quantidade de reagentes químicos, não leva a formação de coprodutos ou de impurezas. Alguns dos principais métodos físicos de obtenção de nanopartículas incluem moagem de alta energia com bolas, microondas, radiação a laser e secagem por spray. ${ }^{188}$ Entre os métodos químicos de síntese de (nano)partículas, podemos citar o método hidrotermal e método sol-gel. A síntese pelo método hidrotermal ocorre em um recipiente selado em condições de pressão e temperatura acima da ambiente. ${ }^{189} \mathrm{O}$ método sol-gel é um dos métodos mais utilizados mundialmente para preparação de nanopartículas. Nesse método, é possível controlar a estrutura e a cinética do processo, além do controle da composição química do produto final. ${ }^{190}$

Além das partículas, compósitos também podem ser formados por fibras. Esses materiais são caracterizados principalmente por serem leves e apresentarem elevadas propriedades mecânicas, resistência à corrosão e durabilidade. ${ }^{191}$ Fibras de carbono com diâmetro em escala nanométrica (por exemplo, nanofibras de carbono e nanotubos de carbono) podem significantemente melhorar as propriedades de biomateriais convencionais, tornando possível o desenvolvimento de novos biomateriais compósitos, com aplicações em medicina regenerativa e em tratamento de câncer. ${ }^{191} \mathrm{~A}$ principal vantagem dos biomateriais compósitos com fibras de carbono inclui a melhora das propriedades mecânicas, boa biocompatibilidade e alta estabilidade. ${ }^{192}$ 
Nanofolhas também podem ser constituintes de materiais nanocompósitos. São caracterizadas por sua estrutura bidimensional, com monocamada plana com espessura entre 1-100 nm. ${ }^{193}$ Devido à grande relação superfície/volume, nanofolhas têm elevada resistência mecânica e podem ser facilmente funcionalizadas com diferentes biomoléculas. ${ }^{194}$ Nanofolhas podem interagir com polímeros por meio de interações hidrofóbicas, adsorção física, força de Van der Waals e atração eletrostática. ${ }^{195}$ As nanofolhas podem ser classificadas de acordo com sua constituição em nanofolhas poliméricas, nanofolhas metálicas e nanofolhas não metálicas. ${ }^{196}$ As nanofolhas de maior interesse para aplicações biomédicas são as nanofolhas metálicas e não metálicas devido suas propriedades de resistência mecânica, estabilidade coloidal e fototérmica e biocompatibilidade. ${ }^{194}$

Propriedades físicas, mecânicas e biológicas de compósitos e nanocompósitos são interrelacionadas e dependentes de características das partículas, fibras ou folhas que os compõe (geometria, composição, tamanho e distribuição). ${ }^{197}$ De acordo com Marghalani, ${ }^{198}$ a geometria e o tamanho das partículas em resinas dentárias têm um grande efeito na rugosidade superficial destes compósitos. De maneira geral, partículas menores levam a formação de uma resina compósita uniforme. Em relação as propriedades mecânicas, Park et al. ${ }^{199}$ observaram maior resistência à fratura em compósitos poliméricos, quando foi utilizada menor proporção em massa de nanotubos de carbono. Por outro lado, outras propriedades mecânicas foram otimizadas quando os nanotubos de carbono se encontravam uniformemente dispersos na matriz polimérica.

Os compósitos e nanocompósitos mais adequados como biomateriais são os formados por polímeros e biocerâmicas. ${ }^{200,201} \mathrm{~A}$ incorporação de cerâmicas a matrizes poliméricas evita as indesejáveis propriedades mecânicas das cerâmicas, como alta fragilidade e baixa resistência a fratura, permitindo aplicações na regeneração de tecidos, como o ósseo. ${ }^{202} \mathrm{Se}$ forem incorporadas nanopartículas bioativas e bioabsorvíveis a matrizes poliméricas biodegradáveis, os nanocompósitos resultantes têm outras propriedades melhoradas além das mecânicas, ${ }^{203,204}$ como adesão, proliferação e diferenciação celular. $^{205}$

Nanopartículas, nanofolhas ou nanotubos cerâmicos intercaladas com fármacos incorporados em matrizes biopoliméricas podem ser utilizados como sistema de entrega controlada, ou de proteção de agentes ativos em dispositivos biomédicos. ${ }^{187,206}$ Biomateriais nanocompósitos a base de polímeros e nanopartículas de prata estão sendo utilizados em dispositivos dentários e médicos devido suas às excelentes propriedades antimicrobianas. ${ }^{207}$

\section{TÉCNICAS PARA OBTENÇÃO DE BIOMATERIAIS POLIMÉRICOS}

Vários métodos são utilizados para fabricar nanoestruturas poliméricas nos formatos 1,2 e 3D, incluindo eletrofiação, ${ }^{208}$ fiação por sopro em solução, ${ }^{123}$ impressão $3 \mathrm{D},{ }^{209} \mathrm{e}$ técnicas de formação de filmes como automontagem, ${ }^{210}$ Langmuir-Blodgett, ${ }^{211}$ camada por camada e evaporação de solvente. ${ }^{212}$ Essas serão abordadas neste artigo de revisão.

\section{Eletrofiação}

A eletrofiação (electrospinning) é baseada no uso de forças eletrostáticas para o preparo de fibras com diferentes composições, morfologias e diâmetros de micrômetros a alguns nanômetros. ${ }^{213}$ Essa técnica remonta aos estudos de Rayleigh em $1882^{214}$ e John Zeleny em $1914,{ }^{215}$ porém, só em 1990 ganhou destaque com os trabalhos de Darrell Reneker e Jayesh Doshi ${ }^{216}$ que demonstraram formação de fibras com diversas moléculas orgânicas. A eletrofiação tem sido usada na preparação de micro/nanofibras poliméricas para medicina regenerativa, engenharia de tecidos, tratamento de água e sensores. ${ }^{208,213,217,218} \mathrm{O}$ arranjo experimental típico para eletrofiação é composto por uma fonte de alta voltagem, uma bomba de controle de vazão, um recipiente para a solução, um capilar e coletor metálicos, conforme mostra a Figura $1 .{ }^{219}$ A eletrofiação é governada por um processo eletrodinâmico durante o qual uma solução, suspensão ou polímero fundido é injetado sob fluxo controlado através do capilar formando uma gota na ponta do capilar. Essa gota é submetida a um campo elétrico criado pela alta voltagem aplicada entre o capilar e o coletor. Com o campo aumenta-se a densidade de carga de mesmo sinal na superfície da gota, deformando-a na forma de cone, denominado cone de Taylor, a partir do qual são ejetados jatos finos carregados eletricamente. ${ }^{219,220}$ Esses jatos são alongados e chicoteados no percurso entre o capilar e o coletor. Nessa fase ocorre a solidificação das fibras depositadas na superfície do coletor, formando-se um não-tecido. ${ }^{219,221}$

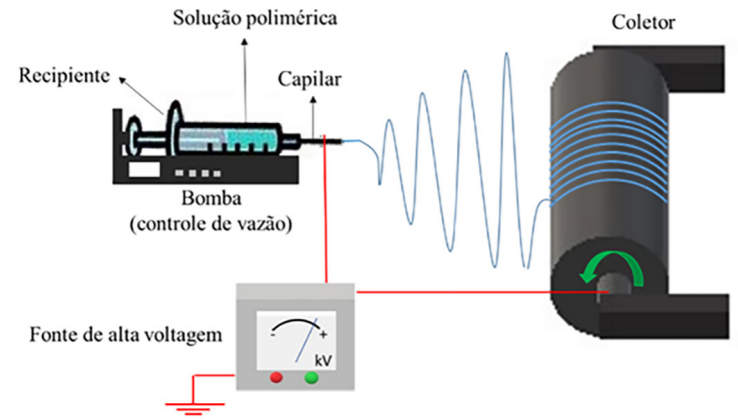

Figura 1. Representação esquemática do arranjo experimental para eletrofiação. Adaptado da Ref. 222. Copyright 2019, com permissão da Springer

A probabilidade de formação, a morfologia e o diâmetro das fibras dependem das características das soluções/suspensões/ polímero fundido (ex. viscosidade, condutividade, tensão superficial, e concentração polimérica), dos parâmetros de processo (voltagem aplicada, vazão de solução polimérica, diâmetro e estrutura do capilar, distância capilar-coletor, e tipo de coletor) e das condições de temperatura e umidade relativa do ambiente..$^{223,224}$ Tem havido grande progresso em sistemas de eletrofiação com diferentes configurações para melhorar o controle sobre a morfologia e diâmetro das fibras, além de aumentar a versatilidade em termos de estrutura e capacidade de produção de fibras. Dentre essas configurações citam-se a eletrofiação coaxial, eletrofiação de campo próximo, eletrofiação multijato e eletrofiação sem capilar. O ajuste das configurações do equipamento, da composição e dos parâmetros de eletrofiação possibilita o controle da morfologia, diâmetro médio e orientação das fibras, bem como as características dos não-tecidos. ${ }^{213}$

Muitos polímeros sintéticos e naturais, e misturas de polímeros, têm sido usados na eletrofiação de solução. A eletrofiação de polissacarídeos tais como quitosana, ${ }^{93}$ goma guar ${ }^{225}$ e alginato ${ }^{225}$ geralmente envolve o uso de soluções aquosas, porém, a obtenção de nanofibras formadas somente por essas macromoléculas consiste em grande desafio. Uma das estratégias adotadas para viabilizar a eletrofiação desses polímeros envolve a combinação compolímeros sintéticos facilmente eletrofiáveis tais como poli(óxido de etileno) (PEO), ${ }^{226}$ poli ( $\varepsilon$-caprolactona) (PCL) ${ }^{227}$ e álcool polivinilico (PVA) ${ }^{93}$ Algumas limitações da eletrofiação para a escala industrial são a baixa taxa de produção, gerando alto custo por grama de nanofibras, e o uso de solventes orgânicos que trazem preocupações econômicas e ambientais. ${ }^{228}$ Após a eletrofiação, parte do solvente pode ficar retido nas fibras, o que aumenta a citotoxicidade do material. A taxa de produção de nanofibras pode ser melhorada com sistemas 
de eletrofiação multi-jato (multinozzle electrospinning). ${ }^{229}$ Podese, também, usar aparatos de eletrofiação sem capilar (needleless electrospinning), em que as fibras são ejetadas diretamente de soluções de eletrofiação armazenadas em banhos que atuam como um dos eletrodos. ${ }^{230}$ Apesar de promissoras, essas estratégias requerem equipamentos mais complexos e de custo elevado. Nesse sentido, técnicas como a fiação por sopro em solução têm sido propostas, como discutido no próximo tópico.

\section{Fiação por sopro em solução}

A técnica de fiação por sopro em solução (SB-Spinning, do inglês solution blow spinning) é alternativa às técnicas para produção de fibras poliméricas, tais como a fiação de géis ( $\mathrm{gel}$ spinning), fiação por fusão (melt spinning), eletrofiação (electrospinning), fiação por sopro de ar quente (melt blowing) e fiação por solução (solution spinning), a qual pode ocorrer a seco (dry spinning) ou em via úmida (wet spinning). ${ }^{123,231} \mathrm{O}$ processo $S B$-Spinning utiliza elementos conceituais da eletrofiação e da fiação no estado fundido para produzir fibras com diâmetros nas escalas micro e nanométricas. ${ }^{232} \mathrm{~A}$ técnica permite obter fibras com diâmetros equivalentes aos obtidos pela eletrofiação, porém com cerca de uma a duas ordens de grandeza inferiores aos produzidos por técnicas convencionais de fiação, como fiação por fusão ou por solução. ${ }^{232}$ Caracteriza-se pela alta produtividade e baixo custo, viabilizando a produção de fibras em escala comercial. ${ }^{233} \mathrm{Na}$ técnica $S B$-spinning não são necessárias altas voltagens como na eletrofiação, o que é vantajoso por permitir a fiação simultânea de células ou outras (bio)moléculas, tais como proteínas, vitaminas e hormônios. ${ }^{232}$ As fibras podem ser depositadas sobre qualquer tipo de superfície, inclusive tecidos vivos. ${ }^{234}$

A Figura 2 apresenta o aparato experimental da técnica $S B$ Spinning. A solução polimérica a ser fiada é inserida em uma seringa acoplada a uma bomba com taxa de injeção ou de alimentação constante. ${ }^{213}$ Um cilindro de gás comprimido ou um compressor é usado para a ejeção de gás, que pode ser ar, nitrogênio ou argônio, sob pressão controlada por um manômetro. A seringa e o gás comprimido são conectados a um sistema de bocais concêntricos, em que a solução polimérica é alimentada no bocal interno, podendose ajustar a projeção deste, enquanto o fluxo de gás é efetuado no bocal externo. ${ }^{213}$ A solução polimérica é bombeada através do bocal interno até atingir o bocal externo, local onde a pressão é mais elevada devido ao fluxo de gás pressurizado. ${ }^{231}$ Essa pressão reduz-se à pressão atmosférica $\left(\mathrm{P}_{\mathrm{atm}}\right)$ na saída do sistema de bocais, aumentando a velocidade do gás que contorna o bocal interno, e, conforme o princípio de Bernoulli, resulta em conversão da variação da pressão em energia cinética. A geometria dos bocais leva à criação de uma região de baixa pressão nas adjacências do bocal interno, de maneira a constituir uma gota de solução polimérica na ponta da agulha. ${ }^{231}$ Tal gota adquire um formato cônico, similar ao cone de Taylor da técnica de eletrofiação, estando sua deformação associada à ação de forças de arraste devido à diferença de pressão pela passagem de gás através do bocal externo. Forma-se, então, um jato de solução polimérica do estiramento do cone. ${ }^{231}$ Uma vez expelido, o jato de solução é acelerado até ser depositado sobre o coletor, que pode permanecer estático ou rotacionar a uma velocidade pré-determinada, posicionado a uma certa distância de trabalho. Durante esse trajeto tem-se a evaporação do solvente, verificando-se ao final a formação de fibras com diâmetros nas escalas micro ou nanométricas, dependendo das condições de processamento. ${ }^{231}$ As principais variáveis de processamento de $S B$-spinning com efeito na dimensão e morfologia do material formado incluem: taxa de alimentação; pressão do ar; massa molar e concentração do polímero e distância de trabalho. ${ }^{232}$

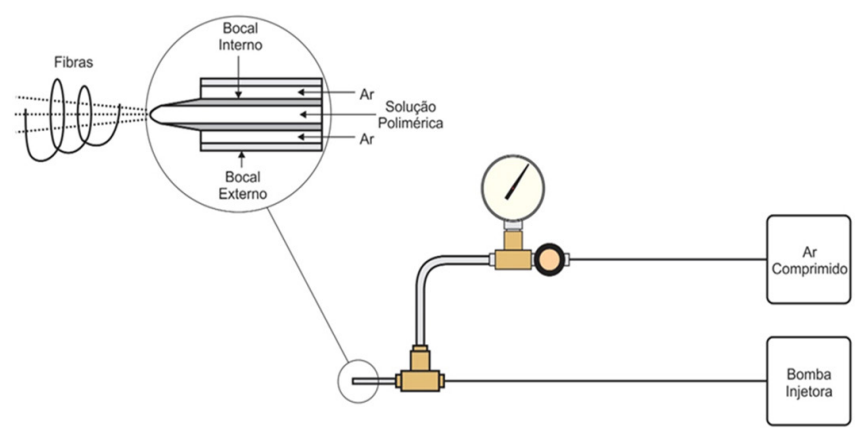

Figura 2. Aparato experimental para produzir fibras poliméricas com fiação por sopro em solução (Fonte: Paschoalin, 2017)23.

\section{Filmes}

Biomateriais em forma de filmes têm sido produzidos com polímeros naturais, polímeros sintéticos, blendas e compósitos, além de biomoléculas ou metais e cerâmicas. ${ }^{18,236,237}$ A possibilidade de incorporar nanopartículas, ${ }^{210,238,239}$ biomateriais, DNA, RNA, ${ }^{240,241}$ proteínas, peptídeos e outros biopolímeros, ${ }^{242,243}$ abre novos caminhos para nanomateriais com estrutura e funções ajustáveis. ${ }^{244}$ Um exemplo é o trabalho de $\mathrm{Xu}$ et al. ${ }^{245}$ em que foi projetada uma superfície de biomaterial multifuncional de lisozima-polifosfato com atividade antibacteriana e fixação eficiente, com proliferação e diferenciação celular. Ressalte-se que a proteína globular lisozima adere a substratos, sendo usada em nanofilmes em interfaces sólidolíquido, vapor-líquido e em substratos. ${ }^{246}$ Iniciaremos o tópico de filmes apresentando estratégias para sua modificação superficial, fator determinante para alcançar biocompatibilidade.

\section{Modificação das superfícies}

A modificação superficial de nanoestruturas poliméricas é necessária quando não há reconhecimento entre o agente biológico e a superfície do material onde será aplicado, ou quando se pretende controlar as propriedades do biomaterial. ${ }^{247}$ As estratégias de funcionalização mais comuns são tratamento com plasma, ${ }^{248}$ tratamento com laser ${ }^{249}$ e modificação com nanopartículas (materiais de carbono, biomoléculas e estruturas inorgânicas). ${ }^{246}$ Nessa última possibilidade, pode-se fazer adsorção física (técnica de automontagem), por meio de ligações covalentes, ou pela combinação destas (Figura 3). A incorporação de nanopartículas em biomateriais pode melhorar seu desempenho, por aumentar a adesão celular, diferenciação e integração das células no ambiente circundante. ${ }^{244}$ É essencial preservar a bioatividade, que pode ser vulnerável à inativação ou degradação. ${ }^{250} \mathrm{~A}$ imobilização covalente

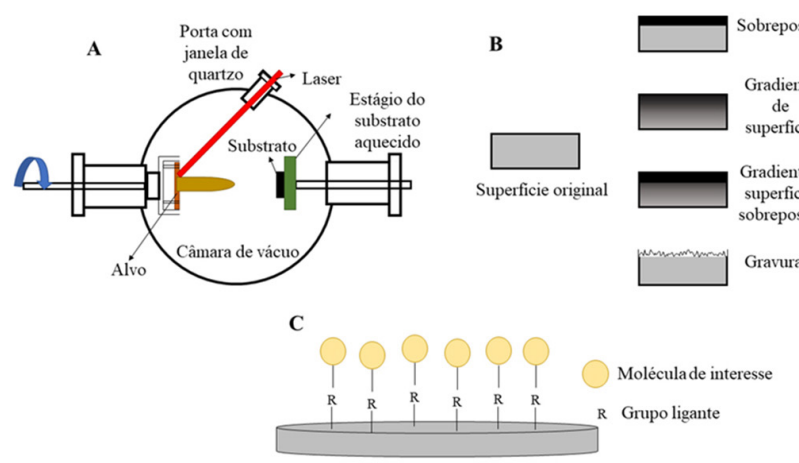

Figura 3. Representação esquemática da modificação de superfície (A) utilizando deposição por laser pulsado. Adaptado de Bellardita et al. $;^{252}$ (B) utilizando diferentes métodos de tratamento com plasma. Adaptado de Chu et al. ${ }^{253}$ e (C) por imobilização covalente 
atende a alguns desses requisitos, gerando biomateriais bioativos com biofuncionalidade e permitindo um estímulo localizado. ${ }^{251}$ Essas características podem ser otimizadas na escolha da rota de imobilização das biomoléculas, visando a maior exposição dos sítios bioativos na superfície do biomaterial.

Embora sejam processos mais complexos, as estratégias de imobilização covalente podem resultar em maior quantidade de fatores de crescimento imobilizados do que usando imobilização não-covalente. ${ }^{254} \mathrm{~A}$ ligação covalente entre proteínas e superfícies funcionalizadas permite controle da quantidade, orientação, retenção, e distribuição de fatores de crescimento na superfície. ${ }^{255}$ Esse controle proporciona um estímulo contínuo dos receptores celulares, induzindo sinal intracelular e expressão negativa desses receptores, ${ }^{256}$ além de o controle espacial aumentar a eficácia dos biomateriais biofuncionalizados. ${ }^{257}$ Nesse cenário, não há interação das biomoléculas com o ambiente circundante, apresentando, portanto, um efeito biológico local, prolongado e com menor dosagem, o que reduz efeitos colaterais indesejados em sítios nãoalvo. ${ }^{258}$ Os grupos funcionais mais explorados na biofuncionalização de superfície são as aminas e os grupos carboxila. ${ }^{259} \mathrm{Na}$ ausência deles, são realizados tratamentos para ativar quimicamente a superfície do biomaterial, como hidrólise e aminólise ${ }^{260}$ para expor grupos carboxila e amina, respectivamente, ou tratamento com plasma, ${ }^{261}$ com agentes reticulantes e reações de foto-iniciação. ${ }^{262} \mathrm{O}$ tratamento com plasma altera a rugosidade da superfície, o que pode afetar a resposta biológica. Reznickova et al. ${ }^{248}$ realizaram tratamento com plasma de argônio em polietileno de diferentes massas molares e nanomorfologias. Os resultados in vitro comprovaram um aumento significativo da adesão das células musculares e vasculares lisas, em comparação com os polímeros não tratados.

$\mathrm{O}$ tratamento a laser pode gerar nanoestruturas superficiais periódicas. Rebollar et al. ${ }^{263}$ modificaram a superfície de folhas de poliestireno com laser, e observaram nanoestruturas na superfície que orientam o alinhamento celular. As mudanças superficiais, químicas ou morfológicas nos biomateriais têm influência positiva na proliferação de células renais embrionárias humanas. As ligações químicas são quebradas pela radiação laser, o que leva a radicais reativos com a atmosfera circundante na superfície. ${ }^{263}$ Um exemplo de modificação topográfica está no trabalho de Sechi et al., ${ }^{264}$ ilustrado na Figura 4. O controle da velocidade da motilidade celular foi observada ao modificar a topografia, com modulação e espaçamento do nanogel de poli ( $\mathrm{N}$-isopropil acrilamida) sobre substratos de vidro e polidimetilsiloxano.

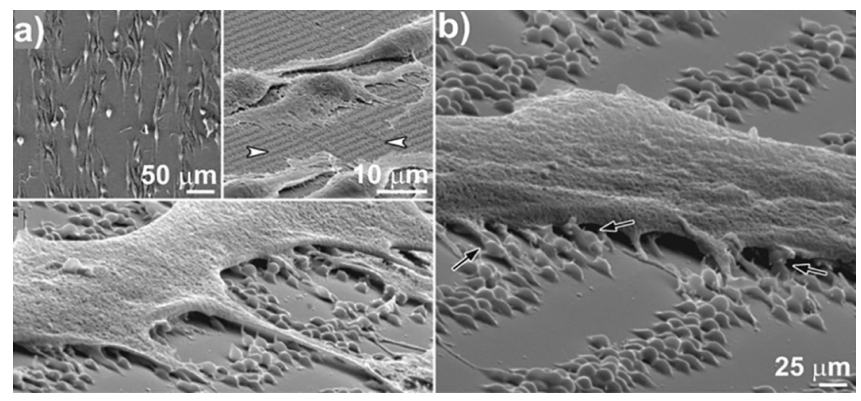

Figura 4. Células de melanoma murinho (B16F1) com estrutura orientada durante a motilidade celular em função da conformação do nanogel poli( $N$ isopropil acrilamida). Reproduzido da Ref. 264 Copyright 2020, com permissão da John Wiley and Sons

\section{Automontagem}

Uma das técnicas mais simples para produzir biomateriais na forma de filmes nanoestruturados é a automontagem por adsorção física, ${ }^{210,246,265,266}$ que permite fabricar arquiteturas controladas com espessuras de alguns nanômetros até micrômetros. Os filmes são originados de interações não covalentes, como ligações de hidrogênio, interações eletrostáticas, interações hidrofóbicas entre as cadeias laterais dos polieletrólitos, interações $\pi-\pi$ e interações de Van der Waals. ${ }^{210,246,266}$ A automontagem pode ser feita pela imersão de um substrato em uma solução contendo íons e/ou moléculas carregadas. Para formar multicamadas, realiza-se a imersão alternada do substrato em soluções de polieletrólitos catiônicos e aniônicos, ou de camadas com afinidade para a adsorção de uma próxima, num processo de fabricação camada por camada (em inglês utiliza-se "layer-by-layer"). As moléculas fracamente adsorvidas são removidas em etapas de lavagem, ${ }^{265}$ como exemplificado na representação esquemática da Figura 5a. Parâmetros como rugosidade, espessura e porosidade dos filmes podem ser controlados empregando-se diferentes substratos e ajustando-se condições experimentais como o tempo de automontagem, temperatura, concentração da solução e pH. ${ }^{265,266}$

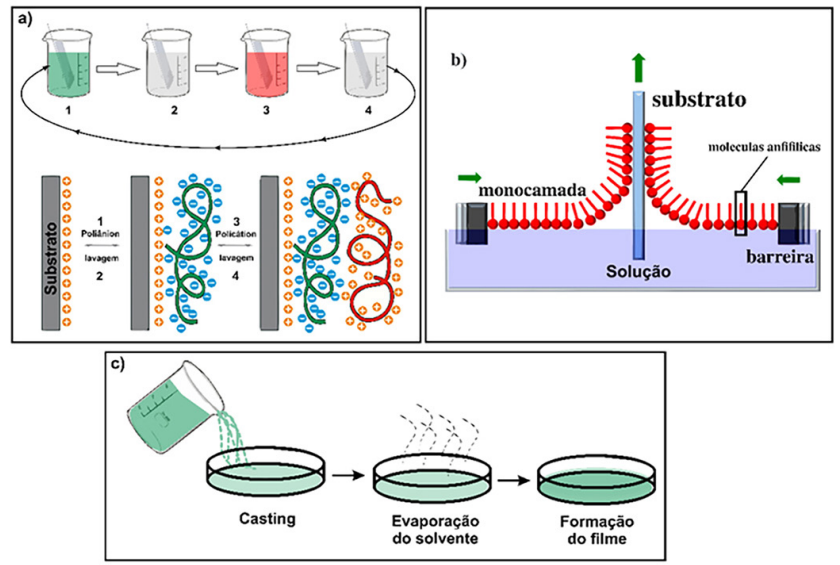

Figura 5. Representação esquemática da produção de filmes com as técnicas de: a) automontagem por adsorção física (Adaptado de Decher, 1997);:267 b) Langmuir-Blodgett (Adaptado de Braunger et al., 2018); ${ }^{268}$ c) solventcasting

\section{Langmuir-Blodgett (LB)}

Os filmes LB consistem em mono ou multicamadas de moléculas anfifílicas, que são transferidas da interface líquido-gás (por exemplo, água-ar) para um substrato. As moléculas anfifílicas possuem duas extremidades, uma hidrofílica e outra hidrofóbica. Na superfície da água elas não se dissolvem, mas quando compactadas por barreiras móveis essas moléculas se organizam preferencialmente com a extremidade hidrofílica voltada para a água e a extremidade hidrofóbica para o ar. Se um substrato, inicialmente imerso, é retirado da solução passando através dessas camadas, as moléculas anfifílicas são transferidas para o substrato (Figura 5b). Esse processo de imersão e retirada pode ser repetido para a deposição de multicamadas num mesmo substrato. ${ }^{211}$ Nos filmes LB, a deposição de camadas ocorre pelo movimento vertical do substrato, ao passo que se o substrato estiver na horizontal formam-se os chamados filmes Langmuir-Schaeffer.

\section{Evaporação de solvente (Solvent Casting) e lixiviação de partículas}

A produção de filmes finos utilizando a evaporação de solvente é fácil, barata e versátil. O método consiste em depositar a solução polimérica (ou biomaterial) sobre um molde e deixar o solvente evaporar, produzindo o filme (Figura 5c). É possível controlar a uniformidade e espessura do filme, além de orientar/alinhar os nanomateriais durante a evaporação. Em Costa Jr. et al., ${ }^{212}$ filmes de quitosana com poli(álcool vinílico) (PVA) foram preparados via 
secagem de solvente e com glutaraldeído como agente reticulante para obter hidrogéis e posteriormente os filmes. A reticulação foi promovida pelo glutaraldeído via adição nucleofílica da amina da quitosana à carbonila do reagente, ${ }^{269} \mathrm{e}$ os filmes foram úteis para a engenharia de tecidos. Essa técnica de evaporação de solvente pode ser combinada com a lixiviação de partículas para gerar materiais com mais porosidade e com controle do tamanho de poros. A lixiviação também pode ser usada em técnicas como eletrofiação, na qual a porosidade é ajustada pela proporção entre o polímero e o agente formador de poros, cujo tamanho determina as dimensões do poro. Os principais agentes formadores de poros são cloreto de sódio, bicarbonato de amônio e glicose.

\section{Impressão 3D}

Diversos métodos são usados para fabricar materiais de suporte tridimensionais com metais, polímeros, cerâmicas, compósitos, incluindo modelação a quente, ${ }^{270}$ espuma de gás ${ }^{271}$ e liofilização. ${ }^{272}$ Esses métodos são limitados pelo uso de solventes citotóxicos e por não oferecerem alto controle da microestrutura interna, o que pode levar à distribuição heterogênea de poros, comprometendo as propriedades mecânicas. ${ }^{273}$ Tecnologias de impressão 3D são alternativas que superam essas limitações. O método de fabricação de forma livre sólida, ou impressão $3 \mathrm{D}$, permite criar estruturas tridimensionais complexas com alta resolução, controle interno da microestrutura e projetado especificamente para cada situação. Técnicas de imagem por ressonância magnética e tomografia computadorizada propiciam o mapeamento da área a ser reconstruída, criando-se um modelo para a impressão 3D. ${ }^{274}$ Os processos de impressão 3D diferem entre si pela natureza do material utilizado (polímeros, cerâmicas, metais ou resinas), pela tecnologia, modo de deposição de camadas, e pelas características do produto (acabamento de superfície, textura, forma geométrica e propriedades mecânicas).

A impressão por modelagem por fusão e deposição (FDM), representada na Figura 6, é uma técnica muito utilizada para produzir materiais de suporte, ${ }^{275-278}$ sendo baseada na extrusão de um polímero ou compósito polimérico. Com o aquecimento do bico extrusor e com o auxílio do motor de rotação, o filamento polimérico é forçado a sair em estado semi-fundido, sendo depositado em uma plataforma (que pode também ser aquecida) camada por camada para obter o objeto tridimensional. ${ }^{279}$ Os materiais de suporte assim produzidos têm integridade estrutural e propriedades mecânicas adequadas devido à fusão das camadas depositadas. $\mathrm{O}$ controle sobre os parâmetros de impressão (espessura e largura da camada polimérica, distância entre as camadas e o ângulo de construção do material de suporte) é essencial para controlar o tamanho e distribuição de poros e para a interconectividade entre os poros. A FDM é uma técnica de baixo custo e alta reprodutibilidade, com a qual materiais tridimensionais podem ser fabricados em curtos intervalos de tempo. ${ }^{280}$ Os filamentos para impressão por FDM devem possuir capacidade de transferência de calor e reologia adequadas, ${ }^{281}$ como os polímeros termoplásticos.. Por exemplo, o PCL tem baixa temperatura de fusão $\left(60^{\circ} \mathrm{C}\right)$ e de transição vítrea $\left(-60^{\circ} \mathrm{C}\right)$, além de alta estabilidade térmica. Mencione-se que o emprego de altas temperaturas impede a incorporação de células vivas ou substâncias biológicas termossensíveis nos materiais impressos. De maneira semelhante ao FDM, a impressão 3D por deposição a baixas temperaturas (MDB) é realizada camada por camada em uma plataforma, porém mantida a temperaturas abaixo de $0{ }^{\circ} \mathrm{C}$. Outra diferença é que o material polimérico se encontra em solução e não em formato de filamento. ${ }^{282}$

O método de sinterização seletiva a laser (SSL) emprega um feixe de laser de $\mathrm{CO}_{2}$ para sinterizar a fase cerâmica, metálica e polimérica (ou composto polimérico) em pó e então construir o

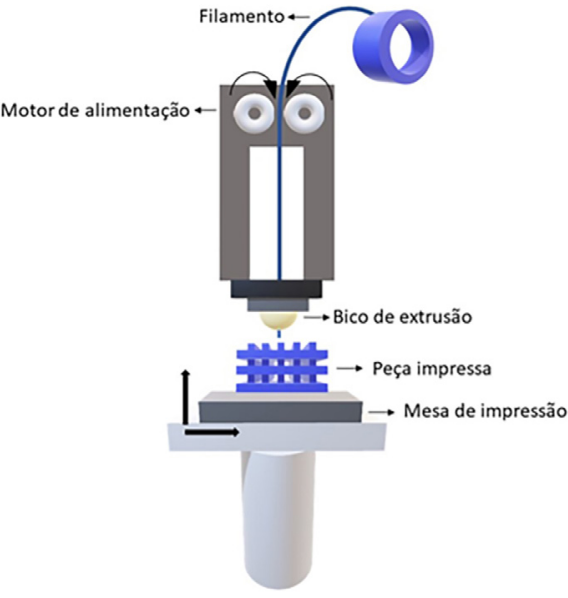

Figura 6. Representação esquemática de uma impressora 3D por modelagem por fusão e deposição

material de suporte camada por camada. Uma vez que uma camada é solidificada, a mesa é movimentada uma camada para baixo. A camada subsequente é depositada sobre a mesa por um rolo, e o processo é repetido até que todo o objeto seja formado. Esse método pode ser utilizado para produção de materiais de suporte com formatos irregulares, incluindo estruturas que contenham canais. Porém, assim como o método FDM, essa técnica não permite incorporar moléculas bioativas devido às altas temperaturas para fundir o material em pó. Por outro lado, a técnica não utiliza solventes orgânicos e componentes tóxicos. ${ }^{283}$

No método de estereolitografia (SLA) é usado um laser de luz ultravioleta para solidificar a resina polimérica por fotopolimerização. ${ }^{284}$ Esse é considerado o primeiro método de impressão 3D, desenvolvido no final da década de 1980. Nele, o feixe de luz é controlado por um projetor digital de luz ou por computador, que então projeta o formato do material de suporte na superfície da resina epóxi (ou material acrílico). A adesão do material na plataforma ocorre após a solidificação da resina. Depois da cura de cada camada, a plataforma se movimenta em sentido oposto ao do crescimento do material de suporte e uma nova camada de resina líquida não curada é depositada sobre a plataforma para um novo processo de cura das camadas subsequentes. Geralmente os materiais de suporte obtidos por essa técnica devem ser submetidos a novos processos de cura em câmara ultravioleta para conversão de grupos que não foram curados durante a impressão. ${ }^{283}$ Podemse fabricar materiais com alta resolução (aproximadamente de 50 $\mu \mathrm{m})$ com polímeros, biocerâmicas e compósitos. ${ }^{282}$ Por outro lado, resíduos tóxicos podem permanecer nas peças impressas, reduzindo a citocompatibilidade e, consequentemente, a aplicação em sistemas vivos (Figura 7).

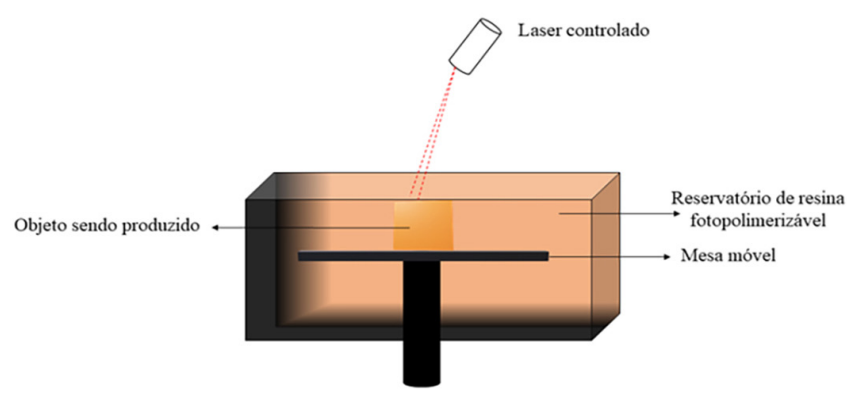

Figura 7. Representação esquemática do sistema de impressão $3 D$ por estereolitografia, um sistema ascendente com varredura a laser. Adaptado de Melchels et al. ${ }^{283}$ 
Métodos de impressão 3D recentes permitem que células vivas sejam incorporadas, chamados de bioimpressão, com as células distribuídas homogeneamente no material de suporte. A restrição é que os materiais fabricados possuem baixa resistência mecânica. ${ }^{285}$ Um dos sistemas de bioimpressão usa tintas e diferentes forças (como a térmica, acústica ou pneumática) para criar e ejetar gotículas de biomaterial através de um orifício, formando o material de suporte. Outro método de bioimpressão é a transferência direta induzida por laser (LIFT): o pulso de laser é transferido a uma camada absorvente, que direciona o feixe à camada de biomaterial, que gerará bolhas de alta pressão para impulsionar o biomaterial gota-por-gota ao substrato como material de suporte. ${ }^{274}$ Os hidrogéis estão entre os principais polímeros utilizados para bioimpressão. São polímeros moldáveis, que podem ser ajustados para mimetizar o ambiente extracelular do corpo. No entanto, esses polímeros apresentam propriedades mecânicas baixas, limitando os locais onde podem ser implantados. ${ }^{286}$ Os polímeros naturais de maior relevância para bioimpressão incluem gelatina, colágeno e alginato. Porém, esses polímeros não suportam os processos de remodelamento e não possuem o mesmo grau de resiliência que os polímeros sintéticos utilizados como biotintas para esse tipo de impressão 3D. ${ }^{287}$ Por fim, os principais polímeros sintéticos adequados para uso como biotintas são polietilenoglicol e poliacrilamida, porém o uso desses polímeros é limitado pela escassez de sítios de ligação para as células. ${ }^{288}$

Polímeros naturais e sintéticos estão sendo utilizados para engenharia de tecidos via fabricação por impressão 3D. ${ }^{289}$ Partículas e nanopartículas estão sendo combinadas com polímeros para produção de materiais de suporte com alta bioatividade, biocompatibilidade e propriedades físico-químicas adequadas às aplicações em biomedicina e engenharia de tecidos ${ }^{290}$ (Tabela 3). Porém a disponibilidade destes materiais em formatos adequados para impressoras 3D continua sendo um desafio. Outras limitações nas técnicas de impressão 3D incluem: (i) impossibilidade de impressão de grandes volumes; (ii) tempo de impressão; (iii) custo das impressoras; (iv) impossibilidade de impressão de diferentes materiais em uma mesma impressora. ${ }^{280}$ Portanto, é necessário o desenvolvimento de novas impressoras com desempenho otimizado. Mencione-se também que o maior obstáculo para que materiais obtidos por impressão 3D cheguem ao mercado reside nos requisitos regulatórios pelas agências responsáveis, como ANVISA e FDA. ${ }^{291}$ Tais requisitos são difíceis de estabelecer principalmente devido à grande variedade de métodos de impressão 3D, o que dificulta criar um guia universal para os métodos de impressão. Há apenas um produto aprovado pelo FDA e comercializado. ${ }^{291}$ Apesar desses desafios, as técnicas de produção de biomateriais 3D são promissoras, como discutido no próximo tópico dessa revisão.

\section{APLICAÇÕES}

Biomateriais constituídos por nanofibras têm sido usados em liberação controlada de bioativos, ${ }^{297,298}$ engenharia de tecidos ${ }^{299,300}$ e medicina regenerativa. ${ }^{301,302} \mathrm{O}$ interesse nesses materiais advém de sua alta razão entre área de superfície e volume, flexibilidade mecânica, facilidade de preparo, possibilidade de modificação da superfície, e estrutura que mimetiza microambientes fisiológicos in vivo. ${ }^{298,303,304}$ Para liberação controlada de agentes terapêuticos, de fármacos a enzimas e células, ${ }^{298,305,306}$ as nanofibras propiciam modulação da cinética de liberação por sua versatilidade em termos de composição, morfologia e diferentes estruturas como fibras coaxiais ${ }^{93}$ e fibras Janus. ${ }^{307}$ As fibras coaxiais, em particular, são interessantes porque a liberação do composto ativo pode ser modulada pela composição da sua estrutura interna e externa. A estrutura coaxial também permite incorporar um ou mais agentes terapêuticos nas diferentes camadas das fibras em uma única etapa. ${ }^{308,309} \mathrm{~A}$ liberação do agente terapêutico das nanofibras pode se dar por estímulos externos como luz, campo magnético, campo elétrico, ultrassom, e variação de temperatura. ${ }^{310-313}$ Essa variedade de possibilidades proporciona um ajuste que garante um tratamento personalizado, pois pode-se dosar o agente terapêutico de acordo com as necessidades do paciente, aumentando a eficácia e reduzindo efeitos colaterais. ${ }^{213}$

$\mathrm{Na}$ medicina regenerativa e engenharia de tecidos, as nanofibras são úteis por sua porosidade e razão superfície/volume, além da similaridade com a matriz extracelular de diversos tecidos. As fibras podem ser depositadas em estruturas tridimensionais e alteradas quanto à composição, superfíce, propriedades mecânica e degradabilidade, permitindo a construção de unidades funcionais a partir de células cultivadas nessas estruturas. ${ }^{314-316}$ Paschoalin et al. ${ }^{123}$ mostraram que as células do sistema imunológico (células dendríticas) não sofreram maturação e não liberaram citotoxinas após o contato com fibras. Ou seja, não reconheceram as nanofibras como "corpo estranho", e células de melanoma apresentaram adesão e motilidade em direção às nanofibras de PLA e às blendas PLA/PEG obtidas por fiação por sopro, como ilustrado na Figura 8. Nanofibras têm sido usadas em curativos e na regeneração óssea, ${ }^{317}$ de cartilagens, ${ }^{318-320}$ tecidos neurais ${ }^{321-323}$ e cardíacos. ${ }^{324,325}$ Estruturas

Tabela 3. Principais características de biomateriais poliméricos obtidos por impressão 3D

\begin{tabular}{|c|c|c|c|}
\hline Compósito & Técnica de impressão 3D & Principais características & Referência \\
\hline PVA/ $\beta$-TCP & FDM & $\begin{array}{l}\text { Scaffolds com canais interconectados; } \\
10,7 \mathrm{kPa} \text { de capacidade de } \\
\text { carregamento; biocompatibilidade com } \\
\text { células de fibroblasto. }\end{array}$ & Chen et al..$^{292}$ \\
\hline PLLA/nanohidroxiapatita & MDB & $\begin{array}{l}\text { Scaffolds com } 80 \% \text { de porosidade; } \\
\text { capacidade de carregamento de } \\
138,5 \mathrm{MPa} \text {; biocompatibilidade com } \\
\text { osteoblastos. }\end{array}$ & Huang et al. ${ }^{293}$ \\
\hline PLGA/hidroxiapatita/ $\beta$-TCP & SSL & $\begin{array}{l}\text { Porosidade } 47 \% \text {; capacidade de } \\
\text { carregamento de } 12,06 \mathrm{MPa} \text {. }\end{array}$ & Simpson et al. ${ }^{294}$ \\
\hline Resinas fotocuráveis/ $\mathrm{Al}_{2} \mathrm{O}_{3}$ & SLA & $\begin{array}{l}\text { Boa dispersão das partículas; grande } \\
\text { comportamento viscoelástico. }\end{array}$ & Song et al. ${ }^{295}$ \\
\hline Fibroblastos e queratinócitos/colágeno & LIFT & $\begin{array}{l}\text { Método de impressão permite que as } \\
\text { células permaneçam vivas; Células são } \\
\text { capazes de formarem tecido após } 10 \\
\text { dias de impressão. }\end{array}$ & Koch et al. ${ }^{296}$ \\
\hline
\end{tabular}


tridimensionas compostas por fibras formam materiais de suporte para modelos in vitro que mimetizam o microambiente fisiológico e patológico de tecidos e órgãos para modelagem de doenças, triagem de drogas e testes de toxicidade..$^{298,326,327}$ Essa abordagem é uma alternativa para prever a toxicidade e eficácia de terapias sem a necessidade de modelos animais, o que também reduz o tempo e custo de desenvolvimento de novos medicamentos. ${ }^{328-331}$ Nanofibras compuseram modelos tumorais in vitro de cânceres de mama, ${ }^{332}$ próstata, ${ }^{333}$ pâncreas, ${ }^{334}$ e colorretal, ${ }^{335}$ que servem para avaliar a progressão da doença e eficácia de tratamentos.
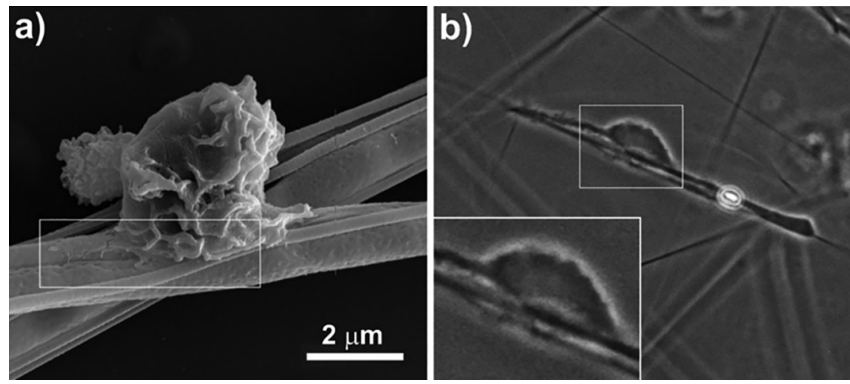

Figura 8. Interação celular com diferentes biomateriais: $a$, b) Célula dendrítica aderida à nanofibra de PLA obtida por fiação por sopro em solução. Destaque para a motilidade induzida pela direção da fibra. Reproduzido da Ref. ${ }^{123}$ Copyright 2020, com permissão da Elsevier

Materiais de suporte fabricados por impressão 3D podem induzir a formação de diferentes tecidos, como o cartilaginoso ${ }^{275}$ e ósseo. ${ }^{336}$ Compósitos e nanocompósitos poliméricos obtidos por impressão 3D são usados em implantes para preservação de alvéolos maxilares e mandibulares após a extração dentária ${ }^{337} \mathrm{Em}$ engenharia de tecidos ósseos as tecnologias de impressão 3D estão sendo aplicadas para reconstrução da região craniofacial com os principais objetivos: a) Substituição: restauração de um defeito através de uma prótese feita sob medida para restaurar a aparência facial normal (em casos de defeitos em grandes áreas ósseas ou tecidos moles, após um trauma ou retirada de tumor); b) Auxiliar a aplicação de enxertos: com propósito de reconstrução óssea criando estrutura essencial e estabilidade primária para enxertos ósseos; c) Estimular o tecido ósseo: regeneração com o objetivo de preservar o osso existente e estimular a osteogênese para reparo ósseo com anatomia normal e restauração de funções. ${ }^{274}$ Impressão 3D também pode ser empregada em sistemas de liberação de fármacos, como em implantes eluidores de fármacos, dispositivos médicos ou pílulas orais com dosagem de fármacos personalizadas para pacientes. ${ }^{338}$ Podem-se criar diferentes faixas de formulações de fármacos que não poderiam ser criadas por métodos convencionais. Essa técnica oferece flexibilidade, com a qual podem ser obtidos diferentes perfis de liberação de medicamentos (desde a liberação controlada ou comprimidos de rápida dissolução) e combinação de diferentes princípios ativos. ${ }^{339,340}$ As técnicas de bioimpressão já permitiram fabricar protótipos de órgãos completos, como tecido cardíaco vascularizado e perfusável, com movimentação de actina- simulando batimentos cardíacos - com compatibilidade (imunológica, celular, bioquímica e anatômica) com o paciente. ${ }^{341}$ Combinando-se células tronco e impressão 3D também podem ser produzidos tecidos hepáticos para implantes, a partir de células do próprio paciente, eliminando riscos de rejeição. ${ }^{342}$

As excelentes perspectivas dos biomateriais na área biomédica só serão tornadas realidade após a superação de alguns desafios. Um dos principais é criar estratégias para fabricar biomateriais nanoestruturados com controle espacial e temporal preciso, o que acelerará a translação dessas tecnologias para aplicações clínicas.
Essas estratégias provavelmente requererão uma convergência das técnicas de eletrofiação, fiação por sopro em solução e impressão 3D. Isso já tem sido feito, e biomateriais obtidos por essas técnicas deverão estar disponíveis comercialmente em futuro próximo.

\section{CONCLUSÕES}

Nesta revisão foram abordados os principais materiais poliméricos e compósitos para aplicação em medicina regenerativa e cultura de tecidos, como biomateriais. A partir de avanços em técnicas de fabricação (eletrofiação, fiação por sopro, formação de filmes e impressão 3D) podem-se produzir materiais que promovem a regeneração de tecidos e liberam substâncias terapêuticas no local afetado. Apesar do considerável progresso em biomateriais, desafios devem ser superados, incluindo a baixa velocidade de produção de materiais de suporte personalizados, necessidade de redução do custo de processamento e garantia de maior eficiência na transferência das novas tecnologias. Para vencer esses desafios serão necessários esforços e investimentos, principalmente para produção em escala de biomateriais que possam atender a demanda mundial.

\section{AGRADECIMENTOS}

Os autores são gratos ao CNPq, Rede AgroNano, SISNANO/ MCTI e FAPESP (processos números: 2016/10636-8; 2017/209734; 2017/ 18725-2; 2017/12174-4, 2018/ 22214-6; 2018/07860-9; 2018/10899-4; 2019/23027-8; 2019/24009-3).

\section{REFERÊNCIAS}

1. Parida, P.; Behera, A.; Chandra Mishra, S.; Int. J. Adv. Appl. Sci. 2012, 1,31 .

2. Gómez, S.; Vlad, M. D.; López, J.; Fernández, E.; Acta Biomater. 2016, 42,341 .

3. Zhao, X.; Bioact. Mater. Med. Des. Appl. 2011, 1.

4. Suresh Kumar, N.; Padma Suvarna, R.; Chandra Babu Naidu, K.; Banerjee, P.; Ratnamala, A.; Manjunatha, H.; Appl. Phys. A: Mater. Sci. Process. 2020, 126, 1 .

5. Williams, D. F.; Biomaterials 2009, 30, 5897.

6. Esteves, A. C. C.; Barros-timmons, A.; Trindade, T.; Quim. Nova 2004, 27, 798.

7. Park, J.; Lakes, R. S. In Biomaterials: A introduction; Park, J., Lakes, R. S., eds.; $3^{\text {rd }}$ ed.; Springer-Verlag: New York, 2007.

8. Okazaki, Y.; Gotoh, E.; Biomaterials 2005, 26, 11.

9. Siqueira, R. L.; Zanotto, E. D.; Quim. Nova 2011, 34, 1231.

10. Sáenz, A.; Rivera, E.; Brostow, W.; Castaño, V.; J. Mater. Educ. 1999, 21, 267.

11. Kohane, D. S.; Langer, R.; Pediatr. Res. 2008, 63, 487.

12. Lee, H. B.; Khang, G.; Lee, J. H. In Biomaterials: principles and applications; Park, J. B., Bronzino, J. D., eds.; CRC Press: Boca Raton, 2002; p. 250.

13. Pişkin, E.; J. Biomater. Sci. Polym. Ed. 1995, 6, 775.

14. Oréfice, R. L.; Hench, L. L.; Brennan, A. B.; J. Braz. Chem. Soc. 2000 , 11,78 .

15. Omanović-Mikličanin, E.; Badnjević, A.; Kazlagić, A.; Hajlovac, M.; Health Technol. (Berl). 2020, 10, 51 .

16. Jockisch, K. A.; Brown, S. A.; Bauer, T. W.; Merritt, K.; J. Biomed. Mater. Res. 1992, 26, 133.

17. Ratner, B. D.; Bryant, S. J.; Annu. Rev. Biomed. Eng. 2004, 6, 41.

18. Pires, A. L. R.; Bierhalz, A. C. K.; Moraes, Â. M.; Quim. Nova 2015, $38,957$.

19. George, A.; Sanjay, M. R.; Srisuk, R.; Parameswaranpillai, J.; Siengchin, S.; Int. J. Biol. Macromol. 2020, 154, 329. 
20. Ahmed, S.; Kanchi, S.; Kumar, G.; Pugazhendhi, A.; Indira, K.; Mary Jacob, J.; Mukesh, M.; Kumar, G. In Handbook of Biopolymers; Jenny Stanford Publishing: Singapore, 2020; pp. 1-22.

21. Puppi, D.; Chiellini, F.; Appl. Mater. Today 2020, 20, 100700.

22. Lee, K. Y.; Mooney, D. J.; Prog. Polym. Sci. 2012, 37, 106.

23. Gallo, N.; Nasser, H.; Salvatore, L.; Natali, M. L.; Campa, L.; Mahmoud, M.; Capobianco, L.; Sannino, A.; Madaghiele, M.; Eur. Polym. J. 2019, 117, 134.

24. Beekmann, U.; Schmölz, L.; Lorkowski, S.; Werz, O.; Thamm, J.; Fischer, D.; Kralisch, D.; Carbohydr. Polym. 2020, 236, 116062.

25. Sampath Udeni Gunathilake, T. M.; Ching, Y. C.; Chuah, C. H.; Rahman, N. A.; Liou, N. S.; Int. J. Biol. Macromol. 2020, 158, 670.

26. Misra, S. K.; Valappil, S. P.; Roy, I.; Boccaccini, A. R.; Biomacromolecules 2006, 7, 2249.

27. Ciecholewska-Juśko, D.; Żywicka, A.; Junka, A.; Drozd, R.; Sobolewski, P.; Migdał, P.; Kowalska, U.; Toporkiewicz, M.; Fijałkowski, K.; Carbohydr. Polym. 2021, 253, 117247.

28. Pour-Esmaeil, S.; Sharifi-Sanjani, N.; Khoee, S.; Taheri-Qazvini, N.; Carbohydr. Polym. 2020, 241, 116322.

29. Aki, D.; Ulag, S.; Unal, S.; Sengor, M.; Ekren, N.; Lin, C. C.; Yllmazer, H.; Ustundag, C. B.; Kalaskar, D. M.; Gunduz, O.; Mater. Des. 2020, 196, 109094.

30. Yu, S.; Ding, L.; Lin, H.; Wu, W.; Huang, J.; Biosens. Bioelectron. 2019, $146,111760$.

31. Ratajczak, K.; Stobiecka, M.; Carbohydr. Polym. 2020, 229, 115463.

32. Smitha, K. T.; Anitha, A.; Furuike, T.; Tamura, H.; Nair, S. V.; Jayakumar, R.; Colloids Surf., B 2013, 104, 245.

33. Ding, X.; Yu, W.; Wan, Y.; Yang, M.; Hua, C.; Peng, N.; Liu, Y.; Carbohydr. Polym. 2020, 245, 116493.

34. Wang, Y.; Fu, C.; Wu, Z.; Chen, L.; Chen, X.; Wei, Y.; Zhang, P.; Carbohydr. Polym. 2017, 174, 723.

35. Ma, M.; Zhong, Y.; Jiang, X.; Carbohydr. Polym. 2020, 236, 116096.

36. Cui, Y.; Wu, Q.; He, J.; Li, M.; Zhang, Z.; Qiu, Y.; Arabian J. Chem. 2020, 13, 7418 .

37. Narayanan, K. B.; Zo, S. M.; Han, S. S.; Int. J. Biol. Macromol. 2020, 149,724

38. Shafabakhsh, R.; Yousefi, B.; Asemi, Z.; Nikfar, B.; Mansournia, M. A.; Hallajzadeh, J.; Carbohydr. Polym. 2020, 242, 116403.

39. Augustine, R.; Rehman, S. R. U.; Ahmed, R.; Zahid, A. A.; Sharifi, M.; Falahati, M.; Hasan, A.; Int. J. Biol. Macromol. 2020, 156, 153.

40. Sahranavard, M.; Zamanian, A.; Ghorbani, F.; Shahrezaee, M. H.; Bioprinting 2020, 17, e00063.

41. Ahsan, S. M.; Thomas, M.; Reddy, K. K.; Sooraparaju, S. G.; Asthana, A.; Bhatnagar, I.; Int. J. Biol. Macromol. 2018, 110, 97.

42. Fernando, I. P. S.; Lee, W. W.; Han, E. J.; Ahn, G.; Chem. Eng. J. 2020, $391,123823$.

43. Zhang, M.; Zhao, X.; Int. J. Biol. Macromol. 2020, 162, 1414.

44. Venkatesan, J.; Bhatnagar, I.; Manivasagan, P.; Kang, K. H.; Kim, S. K.; Int. J. Biol. Macromol. 2015, 72, 269.

45. Hernández-González, A. C.; Téllez-Jurado, L.; Rodríguez-Lorenzo, L. M.; Carbohydr. Polym. 2020, 229, 115514.

46. Ranjan, P.; Parihar, A.; Jain, S.; Kumar, N.; Dhand, C.; Murali, S.; Mishra, D.; Sanghi, S. K.; Chaurasia, J. P.; Srivastava, A. K.; Khan, R.; Anal. Biochem. 2020, 610, 113996.

47. Kikuchi, N.; May, M.; Zweber, M.; Madamba, J.; Stephens, C.; Kim, U.; Mobed-Miremadi, M.; Sensors 2020, 20, 1145.

48. Huang, G.; Huang, H.; J. Control. Release 2018, 278, 122

49. Zhong, W.; Pang, L.; Feng, H.; Dong, H.; Wang, S.; Cong, H.; Shen, Y.; Bing, Y.; Carbohydr. Polym. 2020, 238, 116204.

50. Graça, M. F. P.; Miguel, S. P.; Cabral, C. S. D.; Correia, I. J.; Carbohydr. Polym. 2020, 241, 116364.

51. Collins, M. N.; Birkinshaw, C.; Carbohydr. Polym. 2013, 92, 1262.
52. Agarwal, G.; Agiwal, S.; Srivastava, A.; Int. J. Biol. Macromol. 2020, 165, 388 .

53. Dervisevic, M.; Alba, M.; Prieto-Simon, B.; Voelcker, N. H.; Nano Today 2020, 30, 100828.

54. Klemm, D.; Heublein, B.; Fink, H.-P.; Bohn, A.; Angew. Chem., Int. Ed. 2005, 44, 3358.

55. Dash, M.; Chiellini, F.; Ottenbrite, R. M.; Chiellini, E.; Prog. Polym. Sci. 2011, 36, 981.

56. Kang, S.-M.; Lee, J.-H.; Huh, Y. S.; Takayama, S.; ACS Biomater. Sci. Eng. 2020.

57. Collier, J. H.; Camp, J. P.; Hudson, T. W.; Schmidt, C. E.; J. Biomed. Mater. Res. 2000, 50, 574.

58. Ioelovich, M.; BioResources 2008, 3, 1403.

59. Trache, D.; Hussin, M. H.; Haafiz, M. K. M.; Thakur, V. K.; Nanoscale 2017, 9, 1763.

60. Vasconcellos, V. M.; Farinas, C. S.; Chem. Eng. Trans. 2018, 64, 145.

61. Azeredo, H. M. C.; Barud, H.; Farinas, C. S.; Vasconcellos, V. M.; Claro, A. M.; Front. Sustain. Food Syst. 2019, 3.

62. Dos Santos, D. M.; De Lacerda Bukzem, A.; Ascheri, D. P. R.; Signini, R.; De Aquino, G. L. B.; Carbohydr. Polym. 2015, 131.

63. Oprea, M.; Voicu, S. I.; Carbohydr. Polym. 2020, 247, 116683.

64. Bilatto, S.; Marconcini, J. M.; Mattoso, L. H. C.; Farinas, C. S.; Ind. Crops Prod. 2020, 157, 112938.

65. Corrêa, A. C.; de Teixeira, E. M.; Pessan, L. A.; Mattoso, L. H. C.; Cellulose 2010, 17, 1183.

66. Khine, Y. Y.; Stenzel, M. H.; Mater. Horizons 2020, 7, 1727.

67. Leite, L. S. F.; Bilatto, S.; Paschoalin, R. T.; Soares, A. C.; Moreira, F. K. V; Oliveira, O. N.; Mattoso, L. H. C.; Bras, J.; Int. J. Biol. Macromol. 2020, 165, 2974.

68. Picheth, G. F.; Pirich, C. L.; Sierakowski, M. R.; Woehl, M. A.; Sakakibara, C. N.; de Souza, C. F.; Martin, A. A.; da Silva, R.; de Freitas, R. A.; Int. J. Biol. Macromol. 2017, 104, 97.

69. Ullah, S.; Chen, X.; Appl. Mater. Today 2020, 20, 100656.

70. Tommila, M.; Jokilammi, A.; Penttinen, R.; Ekholm, E. In Cellulose Medical, Pharmaceutical and Electronic Applications; InTech, 2013.

71. Torgbo, S.; Sukyai, P.; Polym. Degrad. Stab. 2020, 179, 109232.

72. Sheikhi, A.; Hayashi, J.; Eichenbaum, J.; Gutin, M.; Kuntjoro, N.; Khorsandi, D.; Khademhosseini, A.; J. Control. Release 2019, 294, 53.

73. Sharif, F.; Muhammad, N.; Zafar, T. In Biofibers and Biopolymers for Biocomposites; Springer International Publishing: Cham, 2020; pp. 229-246.

74. Liu, W.; Du, H.; Zhang, M.; Liu, K.; Liu, H.; Xie, H.; Zhang, X.; Si, C.; ACS Sustain. Chem. Eng. 2020, 8, 7536.

75. Ahmad, S. I.; Ahmad, R.; Khan, M. S.; Kant, R.; Shahid, S.; Gautam, L.; Hasan, G. M.; Hassan, M. I.; Int. J. Biol. Macromol. 2020, 164, 526.

76. Zeng, J. B.; He, Y. S.; Li, S. L.; Wang, Y. Z.; Biomacromolecules 2012, 13,1 .

77. Jafari, H.; Bernaerts, K. V.; Dodi, G.; Shavandi, A.; Mater. Sci. Eng., C 2020, 117, 111266

78. Tao, F.; Cheng, Y.; Shi, X.; Zheng, H.; Du, Y.; Xiang, W.; Deng, H.; Carbohydr. Polym. 2020, 230, 115658.

79. Duan, B.; Huang, Y.; Lu, A.; Zhang, L.; Prog. Polym. Sci. 2018, 82, 1.

80. Peng, N.; Yang, M.; Tang, Y.; Zou, T.; Guo, F.; Wu, K.; Wang, X.; Li, X.; Liu, Y.; Int. J. Biol. Macromol. 2019, 130, 615.

81. Zeng, J.-B.; He, Y.-S.; Li, S.-L.; Wang, Y.-Z.; Biomacromolecules 2012 , $13,1$.

82. Andre, R. S.; dos Santos, D. M.; Mercante, L. A.; Facure, M. H. M.; Campana-Filho, S. P.; Mattoso, L. H. C.; Correa, D. S.; J. Environ. Chem. Eng. 2020, 8, 104163.

83. Zhou, Y.; Fu, S.; Pu, Y.; Pan, S.; Ragauskas, A. J.; Carbohydr. Polym. 2014, 112, 277.

84. Liu, H.; Liu, W.; Luo, B.; Wen, W.; Liu, M.; Wang, X.; Zhou, C.; Carbohydr. Polym. 2016, 147, 216 
85. Rinaudo, M.; Prog. Polym. Sci. 2006, 31, 603.

86. Peniche, C.; Argüelles-Monal, W.; Goycoolea, F. M. In Monomers, Polymers and Composites from Renewable Resources; Gandini, A., Belgacem, M. N., ed.; Elsevier: Amsterdam, 2008; pp. 517-542.

87. Santos, D. M. dos; Bukzem, A. de L.; Campana-Filho, S. P.; Carbohydr Polym. 2016, $138,317$.

88. Kalantari, K.; Afifi, A. M.; Jahangirian, H.; Webster, T. J.; Carbohydr. Polym. 2019, 207, 588-600.

89. Nordtveit, R. J.; Vårum, K. M.; Smidsrød, O.; Carbohydr. Polym. 1996 $29,163$.

90. Luo, Y.; Wang, Q.; Int. J. Biol. Macromol. 2014, 64, 353.

91. Saranya, N.; Moorthi, A.; Saravanan, S.; Devi, M. P.; Selvamurugan, N.; Int. J. Biol. Macromol. 2011, 48, 234.

92. Jayakumar, R.; Prabaharan, M.; Sudheesh Kumar, P. T.; Nair, S. V.; Tamura, H.; Biotechnol. Adv. 2011, 29, 322.

93. dos Santos, D. M.; Chagas, P. A. M.; Leite, I. S.; Inada, N. M.; de Annunzio, S. R.; Fontana, C. R.; Campana-Filho, S. P.; Correa, D. S.; Int. J. Biol. Macromol. 2020, 142, 521.

94. Pavinatto, A.; Fiamingo, A.; Bukzem, A. D. L.; Silva, D. S.; Santos, D. M.; Senra, T. A. D.; Facchinatto, W. M.; Campana Filho, S. P. In Chitosan Based Materials and its Applications; Dotto, G. L., ed.; Bentham Science Publishers: Sharjah, 2017; Vol. 3, pp. 107-132.

95. Bukzem, A. L.; Signini, R.; dos Santos, D. M.; Lião, L. M.; Ascheri, D. P. R.; Int. J. Biol. Macromol. 2016, 85, 615.

96. Senra, T. D. A.; Santos, D. M.; Desbrières, J.; Campana-Filho, S. P.; Polym. Int. 2015, 64, 1617.

97. Facchinatto, W. M.; Fiamingo, A.; dos Santos, D. M.; Campana-Filho, S. P.; Int. J. Biol. Macromol. 2019, 124, 828.

98. Varaprasad, K.; Jayaramudu, T.; Kanikireddy, V.; Toro, C.; Sadiku, E. R.; Carbohydr. Polym. 2020, 236, 116025.

99. Pires, A. L. R.; Westin, C. B.; Hernandez-Montelongo, J.; Sousa, I. M. O.; Foglio, M. A.; Moraes, A. M.; Mater. Sci. Eng., C 2020, 112, 110869.

100. Zhang, G.; Xiao, Y.; Yan, J.; Zhang, W.; Mater. Lett. 2020, 270, 127624.

101. Uyen, N. T. T.; Hamid, Z. A. A.; Tram, N. X. T.; Ahmad, N.; Int. J. Biol. Macromol. 2020, 153, 1035.

102. Thomas, D.; KurienThomas, K.; Latha, M. S.; Int. J. Biol. Macromol. 2020, $154,888$.

103. Kim, S.; Jung, S.; Carbohydr. Polym. 2020, 250, 116934.

104. Reakasame, S.; Boccaccini, A. R.; Biomacromolecules 2018, 19, 3-21.

105. Pawar, S. N.; Edgar, K. J.; Biomaterials 2012, 33, 3279-3305.

106. Kristiansen, K. A.; Tomren, H. B.; Christensen, B. E.; Carbohydr. Polym. 2011, 86, 1595.

107. Gunasekaran, V.; Gowdhaman, D.; Ponnusami, V.; Int. J. Biol. Macromol. 2020, 164, 1916.

108. Abdallah, M. M.; Fernández, N.; Matias, A. A.; Bronze, M. do R.; Carbohydr. Polym. 2020, 243, 116441.

109. Vasvani, S.; Kulkarni, P.; Rawtani, D.; Int. J. Biol. Macromol. 2020, 151, 1012.

110. Zhai, P.; Peng, X.; Li, B.; Liu, Y.; Sun, H.; Li, X.; Int. J. Biol. Macromol. 2020, 151, 1224.

111. Fahmy, A.; Kamoun, E. A.; El-Eisawy, R.; El-Fakharany, E. M.; Taha, T. H.; El-Damhougy, B. K.; Abdelhai, F.; J. Braz. Chem. Soc. 2015, 26 , 1466.

112. Kim, H.; Shin, M.; Han, S.; Kwon, W.; Hahn, S. K.; Biomacromolecules 2019, 20, 2889.

113. Domingues, R. M. A.; Silva, M.; Gershovich, P.; Betta, S.; Babo, P.; Caridade, S. G.; Mano, J. F.; Motta, A.; Reis, R. L.; Gomes, M. E.; Bioconjug. Chem. 2015, 26, 1571 .

114. Tiwari, S.; Bahadur, P.; Int. J. Biol. Macromol. 2019, 121, 556.

115. Nair, L. S.; Laurencin, C. T.; Prog. Polym. Sci. 2007, 32, 762.

116. Odian, G. In Principles of Polymerization; Odian, G., ed.; $4^{\text {th }}$ ed.; Wiley \& Sons: Hoboken, 2004
117. Ajioka, M.; Enomoto, K.; Suzuki, K.; Yamaguchi, A.; Bull. Chem. Soc. Jpn. 1995, 2125.

118. Cao, Y.; Andreattat, A.; HeegertJ, A. J.; Smith, P.; Polymer (Guildf). 1989, 101, 2305.

119. Oliveira, J. E.; Medeiros, E. S.; Cardozo, L.; Voll, F.; Madureira, E. H.; Mattoso, L. H. C.; Assis, O. B. G.; Mater. Sci. Eng., C 2013, 33, 844.

120. Bonan, R. F.; Bonan, P. R. F.; Batista, A. U. D.; Sampaio, F. C.; Albuquerque, A. J. R.; Moraes, M. C. B.; Mattoso, L. H. C.; Glenn, G. M.; Medeiros, E. S.; Oliveira, J. E.; Mater. Sci. Eng., C 2015, 48, 372.

121. Bonan, R. F.; Bonan, P. R. F.; Batista, A. U. D.; Perez, D. E. C.; Castellano, L. R. C.; Oliveira, J. E.; Medeiros, E. S.; J. Appl. Polym. Sci. 2017, 134, 1 .

122. Xia, L.; Lu, L.; Liang, Y.; Cheng, B.; RSC Adv. 2019, 9, 35328.

123. Paschoalin, R. T.; Traldi, B.; Aydin, G.; Oliveira, J. E.; Rütten, S.; Mattoso, L. H. C.; Zenke, M.; Sechi, A.; Acta Biomater. 2017, 51, 161.

124. Soares, A. C.; Soares, J. C.; Paschoalin, R. T.; Rodrigues, V. C.; Melendez, M. E.; Reis, R. M.; Carvalho, A. L.; Mattoso, L. H. C.; Oliveira, O. N.; Mater. Sci. Eng., C 2020, 115, 111120.

125. Xiao, S.; Peng, Q.; Yang, Y.; Tao, Y.; Zhou, Y.; Xu, W.; Shi, X.; ACS Appl. Bio Mater. 2020, 3, 346.

126. Daristotle, J. L.; Lau, L. W.; Erdi, M.; Hunter, J.; Djoum, A.; Srinivasan, P.; Wu, X.; Basu, M.; Ayyub, O. B.; Sandler, A. D.; Kofinas, P.; Bioeng. Transl. Med. 2020, 5, 1.

127. Shang, L.; Liu, Z.; Ma, B.; Shao, J.; Wang, B.; Ma, C.; Ge, S.; Bioact. Mater. 2021, 6, 1175.

128. Wang, Y.; Papadimitrakopoulos, F.; Burgess, D. J.; J. Control. Release 2013, 169, 341.

129. Li, X.; He, Y.; Hou, J.; Yang, G.; Zhou, S.; Small 2020, 16, 1.

130. Zahiri, M.; Khanmohammadi, M.; Goodarzi, A.; Ababzadeh, S.; Sagharjoghi Farahani, M.; Mohandesnezhad, S.; Bahrami, N.; Nabipour, I.; Ai, J.; Int. J. Biol. Macromol. 2020, 153, 1241.

131. Fernández-Pérez, J.; Kador, K. E.; Lynch, A. P.; Ahearne, M.; Mater. Sci. Eng., C 2020, 108, 0.

132. Saveleva, M.; Prikhozhdenko, E.; Gorin, D.; Skirtach, A. G.; Yashchenok, A.; Parakhonskiy, B.; Front. Chem. 2020, 7, 1.

133. Sudesh, K.; Lee, Y.-F.; Sridewi, N.; Ramanathan, S.; Int. J. Biotechnol. Wellness Ind. 2016, 4, 103.

134. Kehail, A. A.; Brigham, C. J.; J. Polym. Environ. 2018, 26, 66.

135. Hasan, A.; Memic, A.; Annabi, N.; Hossain, M.; Paul, A.; Dokmeci, M. R.; Dehghani, F.; Khademhosseini, A.; Acta Biomater. 2014, 10, 11.

136. Phukon, P.; Radhapyari, K.; Konwar, B. K.; Khan, R.; Mater. Sci. Eng., C 2014, 37, 314.

137. Shanmuga Sundar, S.; Sangeetha, D.; J. Mater. Sci. 2012, 47, 2736.

138. James, R.; Nagarale, R. K.; Sachan, V. K.; Badalucco, C.; Bhattacharya, P. K.; Kumbar, S. G.; Polym. Adv. Technol. 2014, 25, 1439.

139. Ul Ahad, I.; Bartnik, A.; Fiedorowicz, H.; Kostecki, J.; Korczyc, B.; Ciach, T.; Brabazon, D.; J. Biomed. Mater. Res., Part A 2014, 102, 3298.

140. Singh, J.; Khanra, P.; Kuila, T.; Srivastava, M.; Das, A. K.; Kim, N. H.; Jung, B. J.; Kim, D. Y.; Lee, S. H.; Lee, D. W.; Kim, D. G.; Lee, J. H.; Process Biochem. 2013, 48, 1724.

141. Hong, Y.; Fujimoto, K.; Hashizume, R.; Guan, J.; Stankus, J. J.; Tobita, K.; Wagner, W. R.; Biomacromolecules 2008, 9, 1200.

142. Liu, X.; Lin, T.; Gao, Y.; Xu, Z.; Huang, C.; Yao, G.; Jiang, L.; Tang, Y.; Wang, X.; J.Biomed. Mater. Res., Part B 2012, 100 B, 1556.

143. Nicolae, A.; Grumezescu, A. M.; Recent progress in polyester-urethanes; Elsevier Inc.: Amsterdam, 2019.

144. Dallinger, A.; Keller, K.; Fitzek, H.; Greco, F.; ACS Appl. Mater. Interfaces 2020, 12, 19855.

145. Seal, B. L.; Otero, T. C.; Panitch, A.; Mater. Sci. Eng. Rep. 2001, 34, 147.

146. Arora, B.; Bhatia, R.; Attri, P.; Bionanocomposites: Green materials for a sustainable future; Elsevier Inc.: Amsterdam, 2018. 
147. Martin, V.; Ribeiro, I. A.; Alves, M. M.; Gonçalves, L.; Claudio, R. A.; Grenho, L.; Fernandes, M. H.; Gomes, P.; Santos, C. F.; Bettencourt, A. F.; Mater. Sci. Eng., C 2019, 101, 15.

148. Howard, G. T.; Int. Biodeterior. Biodegrad. 2002, 49, 245.

149. Bernardo, M. P.; Coelho, L. F.; Sass, D. C.; Contiero, J.; Braz. J. Microbiol. 2016.

150. Coelho, L. F.; De Lima, C. J. B.; Rodovalho, C. M.; Bernardo, M. P.; Contiero, J.; Braz. J. Chem. Eng. 2011.

151. Li, Z.; Tan, B. H.; Lin, T.; He, C.; Prog. Polym. Sci. 2016, 62, 22.

152. Low, Y. J.; Andriyana, A.; Ang, B. C.; Zainal Abidin, N. I.; Polym. Eng. Sci. 2020, 1.

153. Shockley, M. F.; Muliana, A. H.; Polym. Degrad. Stab. 2020, 180, 109298.

154. Abrisham, M.; Noroozi, M.; Panahi-Sarmad, M.; Arjmand, M.; Goodarzi, V.; Shakeri, Y.; Golbaten-Mofrad, H.; Dehghan, P.; Seyfi Sahzabi, A.; Sadri, M.; Uzun, L.; Eur. Polym. J. 2020, 131.

155. Lam, C. X. F.; Hutmacher, D. W.; Schantz, J. T.; Woodruff, M. A.; Teoh, S. H.; J. Biomed. Mater. Res. A 2009, 90, 906.

156. Dash, T. K.; Konkimalla, V. B.; J. Control. Release 2012, 158, 15.

157. Nonato, R. V.; Mantelatto, P. E.; Rossell, C. E. V.; Appl. Microbiol. Biotechnol. 2001, 57, 1.

158. Steinbiichel, A.; Valentin, H. E.; Microbiol. Lett. 1995, 128, 219.

159. Mohanna, P. N.; Young, R. C.; Wiberg, M.; Terenghi, G.; J. Anat. 2003, 203, 553.

160. Reusch, R. N.; Sparrow, A. W.; Gardiner, J.; Biochim. Biophys. Acta, Lipids Lipid Metab. 1992, 1123, 33.

161. Kurtz, S. M.; Devine, J. N.; Biomaterials 2007, 28, 4845.

162. Scholes, S. C.; Unsworth, A.; Proceedings of the Institution of Mechanical Engineers, Part H: Journal of Engineering in Medicine 2009, 223, 13.

163. Toth, J. M.; Wang, M.; Estes, B. T.; Scifert, J. L.; Seim, H. B.; Turner, A. S.; Biomaterials 2006, 27, 324.

164. Scolozzi, P.; Martinez, A.; Jaques, B.; J. Craniofac. Surg. 2007, 18, 218.

165. dos Santos, F. S. F.; Ferreira, V. P.; de Sá, M. D.; Fook, M. V. L.; Rev. Mater. 2017, 22.

166. Morrison, C.; Macnair, R.; MacDonald, C.; Wykman, A.; Goldie, I.; Grant, M. H.; Biomaterials 1995, 16, 987.

167. Scotchford, C. A.; Garle, M. J.; Batchelor, J.; Bradley, J.; Grant, D. M.; Biomaterials 2003, 24, 4871.

168. Katzer, A.; Marquardt, H.; Westendorf, J.; Wening, J. V.; Von Foerster, G.; Biomaterials 2002, 23, 1749.

169. Von Wilmowsky, C.; Vairaktaris, E.; Pohle, D.; Rechtenwald, T.; Lutz, R.; Münstedt, H.; Koller, G.; Schmidt, M.; Neukam, F. W.; Schlegel, K. A.; Nkenke, E.; J. Biomed. Mater. Res., Part A 2008, 87, 896.

170. Von Wilmonsky, C.; Lutz, R.; Meisel, U.; Srour, S.; Rupprecht, S.; Toyoshima, T.; Nkenke, E.; Schlegel, K. A.; Pohle, D.; Münstedt, H.; Rechtenwald, T.; Schmidt, M.; J. Bioact. Compat. Polym. 2009, 24, 169.

171. Nieminen, T.; Kallela, I.; Wuolijoki, E.; Kainulainen, H.; Hiidenheimo, I.; Rantala, I.; J. Biomed. Mater. Res., Part A 2006, 79, 963.

172. Zhao, Y.; Wong, H. M.; Wang, W.; Li, P.; Xu, Z.; Chong, E. Y. W.; Yan, C. H.; Yeung, K. W. K.; Chu, P. K.; Biomaterials 2013, 34, 9264.

173. Edwards, S. L.; Werkmeister, J. A.; J. Biomed. Mater. Res., Part A 2012, 100 A, 3326.

174. Zia, K. M.; Bhatti, H. N.; Ahmad Bhatti, I.; React. Funct. Polym. 2007, 67, 675.

175. Bercea, M.; Gradinaru, L. M.; Mandru, M.; Tigau, D. L.; Ciobanu, C.; J. Mol. Liq. 2019, 274, 562.

176. Marzec, M.; Kucińska-Lipka, J.; Kalaszczyńska, I.; Janik, H.; Mater. Sci. Eng., C 2017, 80, 736 .

177. Janik, H.; Marzec, M.; Mater. Sci. Eng., C 2015, 48, 586.

178. Khan, F.; Tanaka, M.; Int. J. Mol. Sci. 2018, 19, 1.

179. Hasanzadeh, E.; Ebrahimi-Barough, S.; Mirzaei, E.; Azami, M.;
Tavangar, S. M.; Mahmoodi, N.; Basiri, A.; Ai, J.; J. Biomed. Mater. Res., Part A 2019, 107, 802.

180. Jiang, X.; Li, J.; Ding, M.; Tan, H.; Ling, Q.; Zhong, Y.; Fu, Q.; Eur. Polym. J. 2007, 43, 1838.

181. Naureen, B.; Haseeb, A. S. M. A.; Basirun, W. J.; Muhamad, F.; Mater. Sci. Eng., C 2021, 118, 111228.

182. Kucinska-Lipka, J.; Gubanska, I.; Janik, H.; Sienkiewicz, M.; Mater. Sci. Eng., C 2015, 46, 166.

183. Bahrami, S.; Solouk, A.; Mirzadeh, H.; Seifalian, A. M.; Composites, Part B 2019, 168, 421.

184. Solanki, A.; Das, M.; Thakore, S.; Carbohydr. Polym. 2017.

185. Christy, P. N.; Basha, S. K.; Kumari, V. S.; Bashir, A. K. H.; Maaza, M.; Kaviyarasu, K.; Arasu, M. V.; Al-Dhabi, N. A.; Ignacimuthu, S.; J. Drug Deliv. Sci. Technol. 2020, 55, 101452.

186. Farokhi, M.; Mottaghitalab, F.; Samani, S.; Shokrgozar, M. A.; Kundu, S. C.; Reis, R. L.; Fatahi, Y.; Kaplan, D. L.; Biotechnol. Adv. 2018, 36, 68.

187. Kargozar, S.; Ramakrishna, S.; Mozafari, M.; Curr. Opin. Biomed. Eng. 2019, 10, 181.

188. Satyanarayana, T.; Int. J. Res. Appl. Sci. Eng. Technol. 2018, 6, 2885.

189. Feng, S.; Xu, R.; Acc. Chem. Res. 2001, 34, 239.

190. Parashar, M.; Shukla, V. K.; Singh, R.; J. Mater. Sci. Mater. Electron. 2020, 31, 3729.

191. Yang, G.; Park, M.; Park, S. J.; Compos. Commun. 2019, 14, 34.

192. Saito, N.; Aoki, K.; Usui, Y.; Shimizu, M.; Hara, K.; Narita, N.; Ogihara, N.; Nakamura, K.; Ishigaki, N.; Kato, H.; Haniu, H.; Taruta, S.; Ahm Kim, Y.; Endo, M.; Chem. Soc. Rev. 2011, 40, 3824.

193. Adithya, S. P.; Sidharthan, D. S.; Abhinandan, R.; Balagangadharan, K.; Selvamurugan, N.; Int. J. Biol. Macromol. 2020, 164, 1960.

194. Li, X.; Shan, J.; Zhang, W.; Su, S.; Yuwen, L.; Wang, L.; Small 2017, 13,1 .

195. Phakatkar, A. H.; Shirdar, M. R.; Qi, M. li; Taheri, M. M.; Narayanan, S.; Foroozan, T.; Sharifi-Asl, S.; Huang, Z.; Agrawal, M.; Lu, Y. peng; Shahbazian-Yassar, R.; Shokuhfar, T.; Mater. Sci. Eng., C 2020, 109.

196. Wu, M.; Hou, P.; Dong, L.; Cai, L.; Chen, Z.; Zhao, M.; Li, J.; Int. J. Nanomedicine 2019, 14, 4781.

197. Sadat-Shojai, M.; Moghaddas, H.; J. Appl. Polym. Sci. 2020, 137, 1.

198. Marghalani, H. Y.; J. Appl. Oral Sci. 2010, 18, 59.

199. Park, S. H.; Bandaru, P. R.; Polymer (Guildf) 2010, 51, 5071.

200. Affatato, S.; Ruggiero, A.; Merola, M.; Composites, Part B 2015, 83, 276.

201. Shue, L.; Yufeng, Z.; Mony, U.; Biomatter 2012, 2, 271.

202. Johari, B.; Kadivar, M.; Lak, S.; Gholipourmalekabadi, M.; Urbanska, A. M.; Mozafari, M.; Ahmadzadehzarajabad, M.; Azarnezhad, A.; Afshari, S.; Zargan, J.; Kargozar, S.; Int. J. Artif. Organs 2016, 39, 524.

203. Esposito Corcione, C.; Gervaso, F.; Scalera, F.; Padmanabhan, S. K.; Madaghiele, M.; Montagna, F.; Sannino, A.; Licciulli, A.; Maffezzoli, A.; Ceram. Int. 2019, 45, 2803.

204. Bose, S.; Vahabzadeh, S.; Bandyopadhyay, A.; Mater. Today 2013, 16 , 496.

205. Pina, S.; Oliveira, J. M.; Reis, R. L.; Adv. Mater. 2015, 27, 1143.

206. Bernardo, M. P.; Rodrigues, B. C. S.; Oliveira, T. D. De; Guedes, A. P. M.; Batista, A. A.; Mattoso, L. H. C.; Clays Clay Miner. 2007, $1,1$.

207. Corrêa, J. M.; Mori, M.; Sanches, H. L.; Cruz, A. D. Da; Poiate, E.; Poiate, I. A. V. P.; Int. J. Biomater. 2015, 2015.

208. Malafatti, J. O. D.; Bernardo, M. P.; Moreira, F. K. V.; Ciol, H.; Inada, N. M.; Mattoso, L. H. C.; Paris, E. C.; Polym. Adv. Technol. 2020, 31, 1377.

209. Song, Y.; Li, Y.; Song, W.; Yee, K.; Lee, K. Y.; Tagarielli, V. L.; Mater. Des. 2017, 123, 154

210. Jandt, K. D.; Adv. Eng. Mater. 2007, 9, 1035.

211. Ariga, K.; Nakanishi, T.; Michinobu, T.; J. Nanosci. Nanotechnol. 2006, 6, 2278. 
212. Costa, E. S.; Mansur, H. S.; Quim. Nova 2008, 31, 1460.

213. dos Santos, D. M.; Correa, D. S.; Medeiros, E. S.; Oliveira, J. E.; Mattoso, L. H. C.; ACS Appl. Mater. Interfaces 2020, acsami.0c12410.

214. Lord Rayleigh; Philos. Mag. Ser. 5 1882, 14, 184.

215. Zeleny, J. ; Phys. Rev. 1914, 3, 69.

216. Doshi, J.; Reneker, D. H.; J. Electrostat. 1995, 35, 151.

217. Chen, H.; Huang, M.; Liu, Y.; Meng, L.; Ma, M.; Sci. Total Environ. 2020, 739, 139944.

218. Mercante, L. A.; Scagion, V. P.; Migliorini, F. L.; Mattoso, L. H. C.; Correa, D. S.; TrAC - Trends Anal. Chem. 2017, 91, 91.

219. Agarwal, S.; Greiner, A.; Wendorff, J. H.; Prog. Polym. Sci. 2013, 38, 963.

220. Reneker, D. H.; Yarin, A. L.; Polymer (Guildf) 2008, 49, 2387.

221. Rieger, K. A.; Birch, N. P.; Schiffman, J. D. ;J. Mater. Chem. B 2013, 1, 4531.

222. Martins, D.; Scagion, V. P.; Schneider, R.; Lemos, A. C. C.; Oliveira, J.; Correa, D. S.; Polym. Agri-Food Appl. 2019, 291.

223. Luo, C. J.; Stoyanov, S. D.; Stride, E.; Pelan, E.; Edirisinghe, M.; Chem. Soc. Rev. 2012, 41, 4708.

224. Xue, J.; Wu, T.; Dai, Y.; Xia, Y.; Chem. Rev. 2019, 119, 5298.

225. Lubambo, A. F.; De Freitas, R. A.; Sierakowski, M. R.; Lucyszyn, N.; Sassaki, G. L.; Serafim, B. M.; Saul, C. K.; Carbohydr. Polym. 2013, 93 , 484.

226. Pakravan, M.; Heuzey, M.-C.; Ajji, A.; Biomacromolecules 2012, 13, 412.

227. dos Santos, D. M.; Leite, I. S.; Bukzem, A. de L.; de Oliveira Santos, R. P.; Frollini, E.; Inada, N. M.; Campana-Filho, S. P.; Carbohydr. Polym. 2018, 186, 110.

228. dos Santos, D. M.; Correa, D. S.; Medeiros, E. S.; Oliveira, J. E.; Mattoso, L. H. C.; ACS Appl. Mater. Interfaces 2020, 12, 45673.

229. Huang, Y.; Song, J.; Yang, C.; Long, Y.; Wu, H.; Mater. Today 2019, 28, 98.

230. Wei, L.; Liu, C.; Mao, X.; Dong, J.; Fan, W.; Zhi, C.; Qin, X.; Sun, R.; Polymers (Basel) 2019, 11, 1.

231. Medeiros, E. S.; Glenn, G. M.; Klamczynski, A. P.; Orts, W. J.; Mattoso, L. H. C.; J. Appl. Polym. Sci. 2010, 116, 2658.

232. Oliveira, J. E.; Moraes, E. A.; Costa, R. G. F.; Afonso, A. S.; Mattoso, L. H. C.; Orts, W. J.; Medeiros, E. S.; J. Appl. Polym. Sci. 2011, 116, 3396.

233. da Silva Parize, D. D.; Foschini, M. M.; de Oliveira, J. E.; Klamczynski, A. P.; Glenn, G. M.; Marconcini, J. M.; Mattoso, L. H. C.; J. Mater. Sci. 2016, 51, 4627.

234. Behrens, A. M.; Casey, B. J.; Sikorski, M. J.; Wu, K. L.; Tutak, W.; Sandler, A. D.; Kofinas, P.; ACS Macro Lett. 2014, 3, 249.

235. Paschoalin, R. T.; Tese de Doutorado, Universidade Federal de São carlos, Brasil, 2017.

236. Guastaldi, A. C.; Aparecida, A. H.; Quim. Nova 2010, 33, 1352.

237. Kawachi, E. Y.; Bertran, C. A.; Reis, alpho R. dos; Alves, O. L.; Quim. Nova 2000, 23, 518.

238. Zarbin, A. J. G.; Quim. Nova 2007, 30, 1469.

239. Blanco, G. E. de O.; Souza, C. W. O. de; Bernardo, M. P.; Zenke, M.; Mattoso, L. H. C.; Moreira, F. K. V.; Mater. Today Commun. 2021, 27.

240. Saaem, I.; Labean, T. H.; Wiley Interdiscip. Rev. Nanomedicine Nanobiotechnology 2013, 5, 150.

241. Grabow, W. W.; Jaeger, L.; Acc. Chem. Res. 2014, 47, 1871.

242. Nam, K. T.; Shelby, S. A.; Choi, P. H.; Marciel, A. B.; Chen, R.; Tan, L.; Chu, T. K.; Mesch, R. A.; Lee, B. C.; Connolly, M. D.; Kisielowski, C.; Zuckermann, R. N.; Nat. Mater. 2010, 9, 454.

243. Wei, G.; Su, Z.; Reynolds, N. P.; Arosio, P.; Hamley, I. W.; Gazit, E.; Mezzenga, R.; Chem. Soc. Rev. 2017, 46, 4661.

244. Van Rijt, S.; Habibovic, P.; J. R. Soc. Interface 2017, 14.

245. Xu, X.; Zhang, D.; Gao, S.; Shiba, T.; Yuan, Q.; Cheng, K.; Tan, H.; Li, J.; Biomacromolecules 2018, 19, 1979.
246. Zhang, X.; Gong, C.; Akakuru, O. U.; Su, Z.; Wu, A.; Wei, G.; Chem. Soc. Rev. 2019, 48, 5564.

247. McMurray, R. J.; Gadegaard, N.; Tsimbouri, P. M.; Burgess, K. V.; McNamara, L. E.; Tare, R.; Murawski, K.; Kingham, E.; Oreffo, R. O. C.; Dalby, M. J.; Nat. Mater. 2011, 10, 637.

248. Reznickova, A.; Novotna, Z.; Kolska, Z.; Kasalkova, N. S.; Rimpelova, S.; Svorcik, V.; Mater. Sci. Eng., C 2015, 52, 259.

249. Nedela, O.; Slepicka, P.; Švorcík, V.; Materials (Basel) 2017, 10.

250. Casanova, M. R.; Reis, R. L.; Martins, A.; Neves, N. M.; Mater. Horizons 2020, 7, 2258.

251. Casanova, M. R.; Alves da Silva, M.; Costa-Pinto, A. R.; Reis, R. L.; Martins, A.; Neves, N. M.; Mater. Sci. Eng., C 2019, 98, 1169.

252. Bellardita, M.; Di Paola, A.; Yurdakal, S.; Palmisano, L. Preparation of catalysts and photocatalysts used for similar processes; Elsevier B.V., 2019.

253. Chu, P. K.; Chen, J. Y.; Wang, L. P.; Huang, N.; Mater. Sci. Eng., R 2002, $36,143$.

254. Koh, H. S.; Yong, T.; Chan, C. K.; Ramakrishna, S.; Biomaterials 2008, 29, 3574.

255. Rahmati, M.; Silva, E. A.; Reseland, J. E.; A Heyward, C.; Haugen, H. J.; Chem. Soc. Rev. 2020, 49, 5178.

256. Kuhl, P. R.; Griffith-Cima, L. G.; Nat. Med. 1996, 2, 1022.

257. Cabanas-Danés, J.; Huskens, J.; Jonkheijm, P.; J. Mater. Chem. B 2014, 2, 2381.

258. Chen, F. M.; Zhang, M.; Wu, Z. F.; Biomaterials 2010, 31, 6279.

259. Ferreira Soares, D. C.; Oda, C. M. R.; Monteiro, L. O. F.; de Barros, A. L. B.; Tebaldi, M. L.; J. Drug Targeting 2019, 27, 355.

260. Nisbet, D. R.; Yu, L. M. Y.; Zahir, T.; Forsythe, J. S.; Shoichet, M. S.; J. Biomater. Sci. Polym. Ed. 2008, 19, 623.

261. Ma, Z.; He, W.; Yong, T.; Ramakrishna, S.; Tissue Eng. 2005, 11, 1149.

262. Ham, D. W.; Jang, E. C.; Son, T. Il; Lee, T. J.; Song, K. S.; J. Ind. Eng. Chem. 2016, 40, 177.

263. Rebollar, E.; Frischauf, I.; Olbrich, M.; Peterbauer, T.; Hering, S.; Preiner, J.; Hinterdorfer, P.; Romanin, C.; Heitz, J.; Biomaterials 2008, 29, 1796.

264. Sechi, A.; Freitas, J. M. G.; Wünnemann, P.; Töpel, A.; Paschoalin, R. T.; Ullmann, S.; Schröder, R.; Aydin, G.; Rütten, S.; Böker, A.; Zenke, M.; Pich, A.; Adv. Mater. Interfaces 2016, 3, 1.

265. Decher, G.; Hong, J. D.; Schmitt, J.; Thin Solid Films 1992, 210-211, 831.

266. Bai, Y.; Luo, Q.; Liu, J.; Chem. Soc. Rev. 2016, 45, 2756.

267. Decher, G.; Science 1997, 277, 1232.

268. Braunger, M. L.; da Silva, E. A.; Awada, H.; de Oliveira, V. J. R.; Silva, H. S.; Bégué, D.; Hiorns, R. C.; Lartigau-Dagron, C.; de Almeida Olivati, C.; Polym. Int. 2018, 67, 1028.

269. De Assis Gonsalves, A.; Araujo, C. R. M.; Soares, N. A.; Goulart, M. O. F.; De Abreu, F. C.; Quim. Nova 2011, 34, 1215.

270. Mao, D.; Li, Q.; Li, D.; Tan, Y.; Che, Q.; Mater. Des. 2018, 160, 1.

271. Liao, X.; Zhang, H.; He, T.; J. Nanomater. 2012, 2012.

272. Badhe, R. V.; Bijukumar, D.; Chejara, D. R.; Mabrouk, M.; Choonara, Y. E.; Kumar, P.; du Toit, L. C.; Kondiah, P. P. D.; Pillay, V.; Carbohydr. Polym. 2017, 157, 1215.

273. Thavornyutikarn, B.; Chantarapanich, N.; Sitthiseripratip, K.; Thouas, G. A.; Chen, Q.; Prog. Biomater. 2014, 3, 61.

274. Maroulakos, M.; Kamperos, G.; Tayebi, L.; Halazonetis, D.; Ren, Y.; J. Dent. 2019, 80, 1 .

275. Yen, H. J.; Tseng, C. S.; Hsu, S. H.; Tsai, C. L.; Biomed. Microdevices 2009, 11, 615

276. Xu, N.; Ye, X.; Wei, D.; Zhong, J.; Chen, Y.; Xu, G.; He, D.; ACS Appl. Mater. Interfaces 2014, 6, 14952.

277. Yang, Y. Y.; Zhao, C. Q.; Wang, L. S.; Lin, J. X.; Zhu, S. Z.; Huang, H. G.; Mater. Sci. Eng., C 2019, 103, 109786. 
278. Bernardo, M. P.; da Silva, B. C. R.; Mattoso, L. H. C.; J. Compos. Mater. 2021.

279. Popescu, D.; Zapciu, A.; Amza, C.; Baciu, F.; Marinescu, R.; Polym. Test. 2018, 69, 157.

280. Ngo, T. D.; Kashani, A.; Imbalzano, G.; Nguyen, K. T. Q.; Hui, D.; Composites, Part B 2018, 143, 172.

281. Chia, H. N.; Wu, B. M.; J. Biol. Eng. 2015, 9, 4.

282. Babilotte, J.; Guduric, V.; Le Nihouannen, D.; Naveau, A.; Fricain, J. C.; Catros, S.; J. Biomed. Mater. Res. - Part B Appl. Biomater. 2019, 107, 2579.

283. Melchels, F. P. W.; Feijen, J.; Grijpma, D. W.; Biomaterials 2010, 31, 6121.

284. Bilatto, S. E. R.; Adly, N. Y.; Correa, D. S.; Wolfrum, B.; Offenhäusser, A.; Yakushenko, A.; Biomicrofluidics 2017, 11.

285. Nyberg, E. L.; Farris, A. L.; Hung, B. P.; Dias, M.; Garcia, J. R.; Dorafshar, A. H.; Grayson, W. L.; Ann Biomed Eng. 2017, 45, 45.

286. Bishop, E. S.; Mostafa, S.; Pakvasa, M.; Luu, H. H.; Lee, M. J.; Wolf, J. M.; Ameer, G. A.; He, T. C.; Reid, R. R.; Genes Dis. 2017, 4, 185.

287. Panwar, A.; Tan, L. P.; Molecules 2016, 21.

288. Skardal, A.; Atala, A.; Ann. Biomed. Eng. 2015, 43, 730.

289. Liu, J.; Sun, L.; Xu, W.; Wang, Q.; Yu, S.; Sun, J.; Carbohydr. Polym. 2019, 207, 297.

290. Li, X.; Cui, R.; Sun, L.; Aifantis, K. E.; Fan, Y.; Feng, Q.; Cui, F.; Watari, F.; Int. J. Polym. Sci. 2014, 2014

291. Ghilan, A.; Chiriac, A. P.; Nita, L. E.; Rusu, A. G.; Neamtu, I.; Chiriac, V. M.; J. Polym. Environ. 2020, 28, 1345.

292. Chen, G.; Chen, N.; Wang, Q.; Compos. Sci. Technol. 2019, 172, 17

293. Huang, J.; Xiong, J.; Liu, J.; Zhu, W.; Chen, J.; Duan, L.; Zhang, J.; Wang, D.; Biomed. Mater. Eng. 2015, 26, S197.

294. Simpson, R. L.; Wiria, F. E.; Amis, A. A.; Chua, C. K.; Leong, K. F.; Hansen, U. N.; Chandrasekaran, M.; Lee, M. W.; J. Biomed. Mater. Res., Part B 2008, 84, 17 .

295. Song, S. Y.; Park, M. S.; Lee, J. W.; Yun, J. S.; Nanomaterials 2018, 8

296. Koch, L.; Deiwick, A.; Schlie, S.; Michael, S.; Gruene, M.; Coger, V.; Zychlinski, D.; Schambach, A.; Reimers, K.; Vogt, P. M.; Chichkov, B.; Biotechnol. Bioeng. 2012, 109, 1855.

297. Cleeton, C.; Keirouz, A.; Chen, X.; Radacsi, N.; ACS Biomater. Sci. Eng. 2019, 5,4183

298. Chen, S.; Li, R.; Li, X.; Xie, J.; Adv. Drug Deliv. Rev. 2018, 132 , 188.

299. Huang, R.; Chen, X.; Dong, Y.; Zhang, X.; Wei, Y.; Yang, Z.; Li, W.; Guo, Y.; Liu, J.; Yang, Z.; Wang, H.; Jin, L.; ACS Appl. Bio Mater. 2020.

300. Wang, L.; Wu, Y.; Hu, T.; Ma, P. X.; Guo, B.; Acta Biomater. 2019, 96, 175 .

301. Chantre, C. O.; Gonzalez, G. M.; Ahn, S.; Cera, L.; Campbell, P. H.; Hoerstrup, S. P.; Parker, K. K.; ACS Appl. Mater. Interfaces 2019, 11, 45498.

302. Li, X.; Zhang, C.; Haggerty, A. E.; Yan, J.; Lan, M.; Seu, M.; Yang, M.; Marlow, M. M.; Maldonado-Lasunción, I.; Cho, B.; Zhou, Z.; Chen, L.; Martin, R.; Nitobe, Y.; Yamane, K.; You, H.; Reddy, S.; Quan, D.-P.; Oudega, M.; Mao, H.-Q.; Biomaterials 2020, 245, 119978.

303. Homaeigohar, S.; Boccaccini, A. R.; Acta Biomater. 2020, 107, 25.

304. Sharifi, F.; Sooriyarachchi, A. C.; Altural, H.; Montazami, R.; Rylander, M. N.; Hashemi, N.; ACS Biomater. Sci. Eng. 2016, 2, 1411.

305. Kajdič, S.; Planinšek, O.; Gašperlin, M.; Kocbek, P.; J. Drug Deliv. Sci. Technol. 2019, 51, 672.

306. Sofi, H. S.; Abdal-hay, A.; Ivanovski, S.; Zhang, Y. S.; Sheikh, F. A.; Mater. Sci. Eng., C 2020, 111, 110756.

307. Yang, J.; Wang, K.; Yu, D.-G.; Yang, Y.; Bligh, S. W. A.; Williams, G. R.; Mater. Sci. Eng., C 2020, 111, 110805.

308. He, P.; Zhong, Q.; Ge, Y.; Guo, Z.; Tian, J.; Zhou, Y.; Ding, S.; Li, H.; Zhou, C.; Mater. Sci. Eng., C 2018, 90, 549.

309. Wang, J.; Windbergs, M.; Int. J. Pharm. 2019, 556, 363.
310. Niiyama, E.; Uto, K.; Lee, C. M.; Sakura, K.; Ebara, M.; Adv. Healthc. Mater. 2019, 8, 1900102.

311. Amarjargal, A.; Brunelli, M.; Fortunato, G.; Spano, F.; Kim, C. S.; Rossi, R. M.; J. Drug Deliv. Sci. Technol. 2019, 52, 8.

312. Li, F.; Qin, Y.; Lee, J.; Liao, H.; Wang, N.; Davis, T. P.; Qiao, R.; Ling, D.; J. Control. Release 2020, 322, 566.

313. Perera, A. S.; Zhang, S.; Homer-Vanniasinkam, S.; Coppens, M. O.; Edirisinghe, M.; ACS Appl. Mater. Interfaces 2018, 10, 15524.

314. Yang, G.; Li, X.; He, Y.; Ma, J.; Ni, G.; Zhou, S.; Prog. Polym. Sci. 2018 $81,80$.

315. Adhikari, U.; An, X.; Rijal, N.; Hopkins, T.; Khanal, S.; Chavez, T.; Tatu, R.; Sankar, J.; Little, K. J.; Hom, D. B.; Bhattarai, N.; Pixley, S. K.; Acta Biomater. 2019, 98, 215.

316. Uehara, T. M.; Paino, I. M. M.; Santos, F. A.; Scagion, V. P.; Correa, D. S.; Zucolotto, V.; Polym. Adv. Technol. 2020, 31, 1437.

317. Chen, H.; Malheiro, A. D. B. F. B.; van Blitterswijk, C.; Mota, C.; Wieringa, P. A.; Moroni, L.; ACS Appl. Mater. Interfaces 2017, 9, 38187.

318. Joseph, C. M.; Reardon, P. J. T.; Konwarh, R.; Knowles, J. C.; Mandal, B. B.; ACS Appl. Mater. Interfaces 2017, 9, 8000.

319. Qu, D.; Zhu, J. P.; Childs, H. R.; Lu, H. H.; Acta Biomater. 2019, 93 111.

320. Chen, W.; Chen, S.; Morsi, Y.; El-Hamshary, H.; El-Newhy, M.; Fan, C.; Mo, X.; ACS Appl. Mater. Interfaces 2016, 8, 24415.

321. Zhou, G.; Chang, W.; Zhou, X.; Chen, Y.; Dai, F.; Anwar, A.; Yu, X.; ACS Appl. Mater. Interfaces 2020, 12, 16168.

322. Hong, M. H.; Hong, H. J.; Pang, H.; Lee, H. J.; Yi, S.; Koh, W. G.; ACS Biomater. Sci. Eng. 2018, 4, 576

323. Chang, Y. C.; Chen, M. H.; Liao, S. Y.; Wu, H. C.; Kuan, C. H.; Sun, J. S.; Wang, T. W.; ACS Appl. Mater. Interfaces 2017, 9, 37623.

324. Streeter, B. W.; Xue, J.; Xia, Y.; Davis, M. E.; ACS Appl. Mater. Interfaces 2019, 11, 18242

325. Castilho, M.; van Mil, A.; Maher, M.; Metz, C. H. G.; Hochleitner, G.; Groll, J.; Doevendans, P. A.; Ito, K.; Sluijter, J. P. G.; Malda, J.; Adv. Funct. Mater. 2018, 28, 1803151.

326. Cavo, M.; Serio, F.; Kale, N. R.; D’Amone, E.; Gigli, G.; del Mercato, L. L.; Biomater. Sci. 2020.

327. Alfano, M.; Nebuloni, M.; Allevi, R.; Zerbi, P.; Longhi, E.; Lucianò, R.; Locatelli, I.; Pecoraro, A.; Indrieri, M.; Speziali, C.; Doglioni, C.; Milani, P.; Montorsi, F.; Salonia, A.; Sci. Rep. 2016, 6, 1.

328. Zhang, B.; Korolj, A.; Lai, B. F. L.; Radisic, M.; Nat. Rev. Mater. 2018 , $3,257$.

329. Bahcecioglu, G.; Basara, G.; Ellis, B. W.; Ren, X.; Zorlutuna, P.; Acta Biomater. 2020, 106, 1

330. Xu, R.; Zhou, X.; Wang, S.; Trinkle, C.; Pharmacol. Ther. 2020, 107668. 331. Mapanao, A. K.; Voliani, V.; Appl. Mater. Today 2020, 19, 100552.

332. Qing, H.; Ji, Y.; Li, W.; Zhao, G.; Yang, Q.; Zhang, X.; Luo, Z.; Lu, T. J.; Jin, G.; Xu, F.; ACS Appl. Mater. Interfaces 2020, 12, 2049.

333. Hartman, O.; Zhang, C.; Adams, E. L.; Farach-Carson, M. C.; Petrelli, N. J.; Chase, B. D.; Rabolt, J. F.; Biomacromolecules 2009, 10, 2019.

334. Ricci, C.; Mota, C.; Moscato, S.; D’Alessandro, D.; Ugel, S.; Sartoris, S.; Bronte, V.; Boggi, U.; Campani, D.; Funel, N.; Moroni, L.; Danti, S.; Biomatter 2014, 4, e955386.

335. Chitcholtan, K.; Asselin, E.; Parent, S.; Sykes, P. H.; Evans, J. J.; Exp. Cell Res. 2013, 319, 75.

336. Serra, T.; Planell, J. A.; Navarro, M.; Acta Biomater. 2013, 9, 5521.

337. Goh, B. T.; Teh, L. Y.; Tan, D. B. P.; Zhang, Z.; Teoh, S. H.; Clin. Oral Implants Res. 2015, 26, 271

338. Trenfield, S. J.; Awad, A.; Madla, C. M.; Hatton, G. B.; Firth, J.; Goyanes, A.; Gaisford, S.; Basit, A. W.; Expert Opin. Drug Deliv. 2019, $16,1081$.

339. Clark, E. A.; Alexander, M. R.; Irvine, D. J.; Roberts, C. J.; Wallace, M. J.; Sharpe, S.; Yoo, J.; Hague, R. J. M.; Tuck, C. J.; Wildman, R. D.; Int. J. Pharm. 2017, 529, 523. 
340. Tian, P.; Yang, F.; Xu, Yuanin, M.; Mei, L.; Yu, L. P.; Lin, W.; Lin, Q. F.; Lv, Z. F.; Huang, S. Y.; Chen, Y. Z.; Drug Dev. Ind. Pharm. 2018, 44, 1918.

341. Noor, N.; Shapira, A.; Edri, R.; Gal, I.; Wertheim, L.; Dvir, T.; Adv. Sci. 2019, 6 .
342. Goulart, E.; Caires-Junior, L. C. de; Telles-Silva, K. A.; Araujo, B. H. S.; Rocco, S. A.; Sforca, M.; Sousa, I.; Kobayashi, L. de; Kobayashi, G. S.; Musso, C. M.; Assoni, A. F.; Oliveira, D.; Caldini, E.; Raia, S.; Lelkes, P. I.; Zatz, M.; Biofabrication 2019, 12, 1. 